\title{
Catchment \& sewer network simulation model to benchmark control strategies within urban wastewater systems
}

Saagi, Ramesh; Flores Alsina, Xavier; Fu, Guangtao; Butler, David; Gernaey, Krist V.; Jeppsson, Ulf

Published in:

Environmental Modelling \& Software

Link to article, DOI:

10.1016/j.envsoft.2015.12.013

Publication date:

2016

Document Version

Peer reviewed version

Link back to DTU Orbit

Citation (APA):

Saagi, R., Flores Alsina, X., Fu, G., Butler, D., Gernaey, K. V., \& Jeppsson, U. (2016). Catchment \& sewer network simulation model to benchmark control strategies within urban wastewater systems. Environmental Modelling \& Software, 78, 16-30. https://doi.org/10.1016/j.envsoft.2015.12.013

\section{General rights}

Copyright and moral rights for the publications made accessible in the public portal are retained by the authors and/or other copyright owners and it is a condition of accessing publications that users recognise and abide by the legal requirements associated with these rights.

- Users may download and print one copy of any publication from the public portal for the purpose of private study or research.

- You may not further distribute the material or use it for any profit-making activity or commercial gain

- You may freely distribute the URL identifying the publication in the public portal 


\title{
CATCHMENT \& SEWER NETWORK SIMULATION MODEL TO BENCHMARK CONTROL STRATEGIES WITHIN URBAN WASTEWATER SYSTEMS
}

\author{
R. Saagi ${ }^{1}$, X. Flores-Alsina ${ }^{2}$, G. Fu ${ }^{3}$, L., D. Butler ${ }^{3}$, K.V. Gernaey ${ }^{2}$, U. Jeppsson ${ }^{1 *}$ \\ ${ }^{1}$ Division of Industrial Electrical Engineering and Automation (IEA), Lund University, Box 118, SE-221 00 \\ Lund, Sweden \\ ${ }^{2}$ CAPEC-PROCESS Research Center, Department of Chemical and Biochemical Engineering, Technical \\ University of Denmark (DTU), Building 229, DK-2800 Kgs. Lyngby, Denmark \\ ${ }^{3}$ Centre for Water Systems, College of Engineering, Mathematics and Physical Sciences, University of \\ Exeter, North Park Road, Harrison Building, Exeter EX4 4QF, UK
}

*Corresponding author:

Ulf Jeppsson, MSc (Eng. Physics), PhD (Ind. Automation), IWA Fellow

Associate professor and deputy head of department

Div of Industrial Electrical Engineering and Automation (IEA)

Dept of Biomedical Engineering (BME)

Faculty of Engineering (LTH)

Lund University http://www.iea.lth.se/

Mailing address: IEA, LTH, PO Box 118, SE-22100 Lund, Sweden

Phone: +46 (0)46 2229287 (office)

Fax: $\quad+46(0) 46142114$ 


\section{RESEARCH HIGHLIGHTS}

- The existing plant-wide Benchmark Simulation Model is spatially extended to include the catchment and sewer system.

- A catchment and sewer system model is developed to describe the dynamics in generation and transport of wastewater during dry and wet weather periods.

- Overflow quality based evaluation criteria are defined for benchmarking of control strategies and structural modifications.

- Case studies depicting the usefulness/application of the catchment and sewer network model are performed. 
(1)

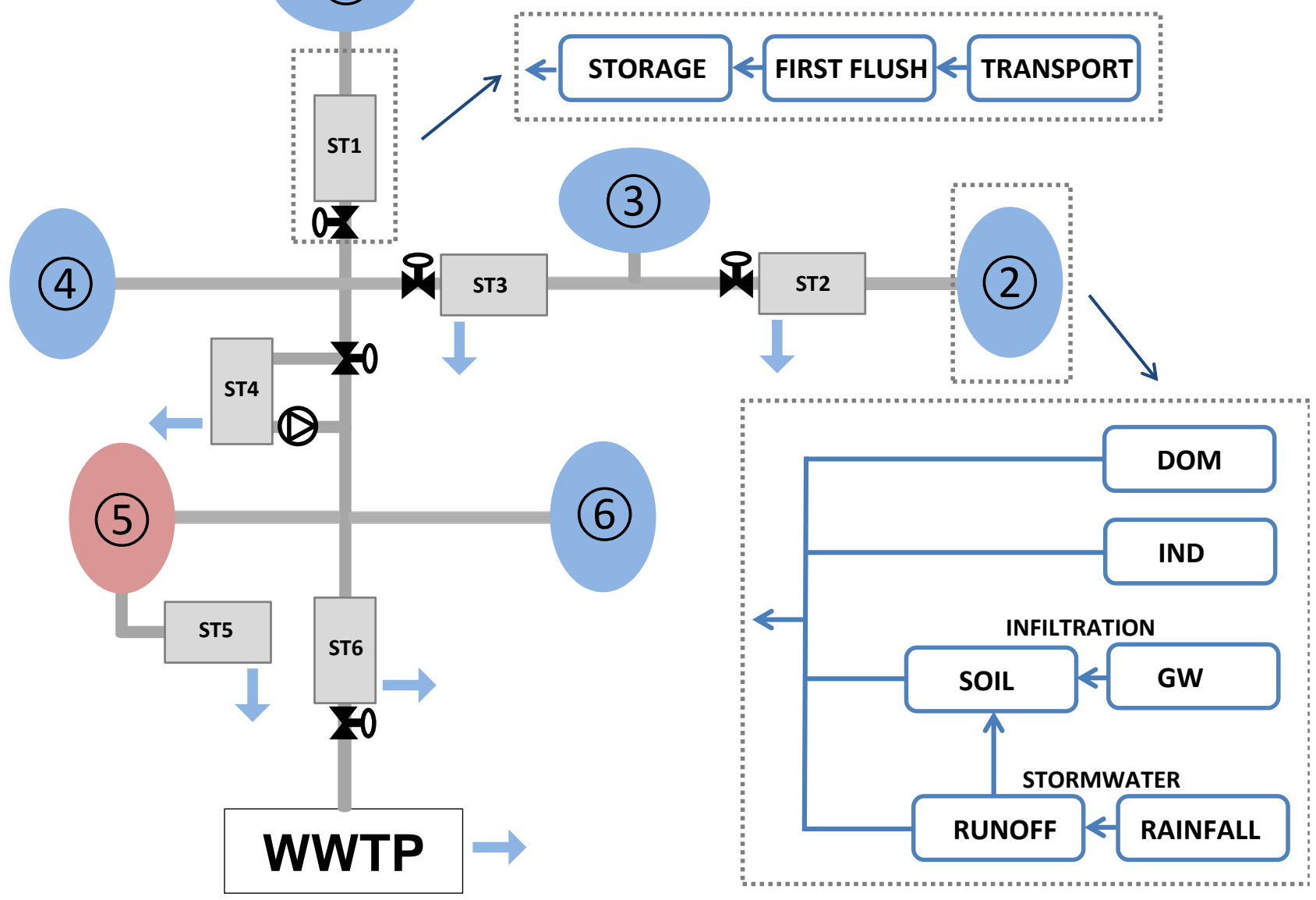


$a$

$\begin{aligned} & A_{\mathrm{c}} \\ & A_{\mathrm{i}}\end{aligned}$
$A_{\text {imp }}$
$A_{\text {soil }}$
$A_{\text {st }}$
$b$
$C_{\max (\mathrm{c})}$

COD

$\mathrm{COD}_{\text {part }}$

$\mathrm{COD}_{\text {sol }}$

$C_{\text {st }}$

EMC

FF

\begin{tabular}{|c|c|}
\hline FFfraction & $\begin{array}{l}\text { Fraction of particulate } \\
\text { material that can settle in the } \\
\text { sewers (first flush block) }\end{array}$ \\
\hline$G W_{\text {in }}$ & $\begin{array}{l}\text { Annual mean groundwater } \\
\text { inflow }\left(\mathrm{m}^{3} / \mathrm{d}\right) \text { (groundwater } \\
\text { block) }\end{array}$ \\
\hline$G W_{\mathrm{in}, \mathrm{SCi}}$ & $\begin{array}{l}G W_{\text {in }} \text { for each sub-catchment } \\
\text { "i" }\left(\mathrm{m}^{3} / \mathrm{d}\right) \text { (groundwater } \\
\text { block) }\end{array}$ \\
\hline$h_{\mathrm{inv}}$ & $\begin{array}{l}\text { Invert level of the tank (m) } \\
\text { (soil block) }\end{array}$ \\
\hline$h_{\max }$ & $\begin{array}{l}\text { Maximum level in the tank } \\
\text { (m) (soil block) }\end{array}$ \\
\hline$h_{\mathrm{min}, \mathrm{st}}$ & $\begin{array}{l}\text { Minimum water level in the } \\
\text { tank (m) (storage block) }\end{array}$ \\
\hline$h_{\mathrm{o}, \mathrm{st}}$ & $\begin{array}{l}\text { Height in the storage tank } \\
\text { when } \mathrm{Q}=\mathrm{Q}_{\max , \mathrm{st}} / 2(\mathrm{~m}) \\
\text { (storage block) }\end{array}$ \\
\hline$h_{\mathrm{ovf}, \mathrm{st}}$ & $\begin{array}{l}\text { Height of the overflow weir } \\
\text { (m) (storage block) }\end{array}$ \\
\hline$h_{\text {soil }}$ & $\begin{array}{l}\text { Height of the soil tank (m) } \\
\text { (soil block) }\end{array}$ \\
\hline$h_{\mathrm{st}}$ & $\begin{array}{l}\text { Water level in the soil tank } \\
\text { (m) (soil block) }\end{array}$ \\
\hline$i$ & Rainfall intensity $(\mathrm{mm} / \mathrm{h})$ \\
\hline
\end{tabular}

Rate of accumulation of pollutant (kg/ha.d) (runoff block)

Catchment area $\left(\mathrm{m}^{2}\right)$

Area for the specific subcatchment "i” $\left(\mathrm{m}^{2}\right)$

Impervious area of the catchment $\left(\mathrm{m}^{2}\right)$

Surface area of the tank $\left(\mathrm{m}^{2}\right)$ (soil block)

Area of the storage tank $\left(\mathrm{m}^{2}\right)$

(storage block)

Decay rate constant (1/d)

(runoff block)

Hourly maximum

concentration for pollutant c $\left(\mathrm{g} / \mathrm{m}^{3}\right)$

Chemical oxygen demand

Particulate COD

Soluble COD

Constant for weir overflow

(storage block)

Event mean concentration $\left(\mathrm{g} / \mathrm{m}^{3}\right)$

Parameter to tune the strength of first flush effect $\left(\mathrm{d}^{-1}\right)$ (first flush block)

\begin{tabular}{|c|c|}
\hline$K_{\text {down }}$ & $\begin{array}{l}\text { Gain for infiltration to } \\
\text { groundwater aquifer (soil } \\
\text { block) }\end{array}$ \\
\hline$K_{\text {inf }}$ & $\begin{array}{l}\text { Gain for infiltration to } \\
\text { sewers (soil block) }\end{array}$ \\
\hline$K_{\mathrm{r}}$ & $\begin{array}{l}\text { Residence time constant for } \\
\text { the reservoir }(\mathrm{d}) \text { (transport } \\
\text { block) }\end{array}$ \\
\hline$K_{\text {soil }}$ & $\begin{array}{l}\text { Soil permeability }(\mathrm{m} / \mathrm{d}) \\
\text { (soil block) }\end{array}$ \\
\hline$L_{\text {weir,st }}$ & $\begin{array}{l}\text { Length of the weir }(\mathrm{m}) \\
\text { (storage block) }\end{array}$ \\
\hline$M_{\mathrm{ff}}$ & $\begin{array}{l}\text { Mass of particulates } \\
\text { accumulated in the sewer } \\
\text { (kg) (first flush block) }\end{array}$ \\
\hline$M_{\mathrm{i}, \mathrm{st}}$ & $\begin{array}{l}\text { Mass of pollutant " } i \text { " in the } \\
\text { storage tank }(\mathrm{kg}) \text { (storage } \\
\text { block) }\end{array}$ \\
\hline$M_{\max , \mathrm{ff}}$ & $\begin{array}{l}\text { Maximum particulate mass } \\
\text { that can accumulate in the } \\
\text { sewer system (kg) (first } \\
\text { flush block) }\end{array}$ \\
\hline$M_{\mathrm{r}}$ & $\begin{array}{l}\text { Mass of pollutant in the } \\
\text { reservoir (kg) (transport } \\
\text { block) }\end{array}$ \\
\hline$M_{\mathrm{s}}$ & $\begin{array}{l}\text { Mass of particulate pollutant } \\
\text { on the surface }(\mathrm{kg}) \text { (runoff } \\
\text { block) }\end{array}$ \\
\hline$n_{\mathrm{ff}}$ & $\begin{array}{l}\text { Parameter to tune the } \\
\text { strength of first flush effect } \\
\text { (first flush block) }\end{array}$ \\
\hline $\mathrm{NH}_{4}^{+}$ & Ammonia \\
\hline $\mathrm{NO}_{3}^{-}$ & Nitrate \\
\hline$N_{\text {ovf }}$ & $\begin{array}{l}\text { Yearly overflow frequency } \\
\text { (events/year) }\end{array}$ \\
\hline$n_{\mathrm{r}}$ & $\begin{array}{l}\text { Number of reservoirs in } \\
\text { series (transport block) }\end{array}$ \\
\hline$O Q I$ & $\begin{array}{l}\text { Overflow quality index (kg } \\
\text { pollution units/d) }\end{array}$ \\
\hline$P E_{\mathrm{c}}$ & $\begin{array}{l}\text { Population equivalents for } \\
\text { the entire catchment }\end{array}$ \\
\hline$P E_{\mathrm{i}}$ & $\begin{array}{l}\text { Population equivalents in } \\
\text { sub-catchment "i") }\end{array}$ \\
\hline $\mathrm{PO}_{4}^{3-}$ & Phosphate \\
\hline$Q_{\mathrm{GW}}$ & $\begin{array}{l}\text { Infiltration to groundwater } \\
\text { aquifer }\left(\mathrm{m}^{3} / \mathrm{d}\right) \text { (soil block) }\end{array}$ \\
\hline$Q_{\text {in,ff }}$ & $\begin{array}{l}\text { Inflow to the first flush } \\
\text { block }\left(\mathrm{m}^{3} / \mathrm{d}\right) \text { (first flush } \\
\text { block) }\end{array}$ \\
\hline$Q_{\text {in, r }}$ & $\begin{array}{l}\text { Inflow to the reservoir } \\
\left(\mathrm{m}^{3} / \mathrm{d}\right) \text { (transport block) }\end{array}$ \\
\hline$Q_{\text {in,st }}$ & $\begin{array}{l}\text { Inflow to the storage tank } \\
\left(\mathrm{m}^{3} / \mathrm{d}\right)(\text { storage block) }\end{array}$ \\
\hline
\end{tabular}




\begin{tabular}{|c|c|c|c|}
\hline$Q_{\mathrm{inf}}$ & $\begin{array}{l}\text { Infiltration to sewers }\left(\mathrm{m}^{3} / \mathrm{d}\right) \\
\text { (soil block) }\end{array}$ & $V_{\text {soil }}$ & $\begin{array}{l}\text { Storage volume of the tank } \\
\left(\mathrm{m}^{3}\right) \text { (soil block) }\end{array}$ \\
\hline$Q_{\text {lim,ff }}$ & $\begin{array}{l}\text { Flow rate limit triggering the } \\
\text { first flush effect }\left(\mathrm{m}^{3} / \mathrm{d}\right) \text { (first }\end{array}$ & $V_{\text {st }}$ & $\begin{array}{l}\text { Volume of the storage tank } \\
\left(\mathrm{m}^{3}\right) \text { (storage block) }\end{array}$ \\
\hline & flush block) & $w$ & Washoff constant $\left(\mathrm{mm}^{-1}\right)$ \\
\hline$Q_{\max , \mathrm{st}}$ & Maximum throttle flow & & (runoff block) \\
\hline$Q_{\text {out,r }}$ & $\begin{array}{l}\left(\mathrm{m}^{3} / \mathrm{d}\right) \text { (storage block) } \\
\text { Outflow from the reservoir } \\
\left(\mathrm{m}^{3} / \mathrm{d}\right) \text { (transnort block) }\end{array}$ & $X_{\mathrm{i}, \mathrm{st}}$ & $\begin{array}{l}\text { Inflow load for pollutant "i" } \\
\text { in the storage tank }(\mathrm{kg} / \mathrm{d})\end{array}$ \\
\hline$Q_{\text {out }, \text { st }}$ & $\begin{array}{l}\text { Outflow from the storage } \\
\text { tank }\left(\mathrm{m}^{3} / \mathrm{d}\right) \text { (storage block) }\end{array}$ & $X_{\text {in,ff }}$ & $\begin{array}{l}\text { Particulate flux entering the } \\
\text { first flush block }(\mathrm{kg} / \mathrm{d}) \text { (first }\end{array}$ \\
\hline$Q_{\text {ovf,st }}$ & Overflow from the storage & & flush block) \\
\hline$Q_{\text {pun }}$ & $\begin{array}{l}\operatorname{tank}\left(\mathrm{m}^{3} / \mathrm{d}\right) \text { (storage block) } \\
\text { Pumping rate at the storage }\end{array}$ & $X_{\mathrm{in}, \mathrm{r}}$ & $\begin{array}{l}\text { Input load to the reservoir } \\
\text { (kg/d) (transport block) }\end{array}$ \\
\hline & $\operatorname{tank}\left(\mathrm{m}^{3} / \mathrm{d}\right)($ storage block $)$ & $X_{\text {out,ff }}$ & Particulate flux leaving the \\
\hline$Q_{\text {throttle,st }}$ & $\begin{array}{l}\text { Throttle flow from the } \\
\text { storage tank }\left(\mathrm{m}^{3} / \mathrm{d}\right) \text { (storage }\end{array}$ & & $\begin{array}{l}\text { first flush block }(\mathrm{kg} / \mathrm{d}) \text { (first } \\
\text { flush block) }\end{array}$ \\
\hline & block) & $X_{\text {out }, \mathrm{r}}$ & Output load from the \\
\hline$R D I_{\text {in }}$ & $\begin{array}{l}\text { Rainfall dependent inflow } \\
\text { from pervious areas }\left(\mathrm{m}^{3} / \mathrm{d}\right)\end{array}$ & & $\begin{array}{l}\text { reservoir }(\mathrm{kg} / \mathrm{d}) \text { (transport } \\
\text { block) }\end{array}$ \\
\hline & (soil block) & $X_{\mathrm{ovf}(\mathrm{c})}$ & Yearly overflow pollutant \\
\hline$r r c$ & Rainfall runoff coefficient & & load for pollutant c (kg) \\
\hline$T_{\operatorname{exc}(\mathrm{c})}$ & $\begin{array}{l}\text { Yearly exceedance duration } \\
\text { for pollutant } \mathrm{c}(\mathrm{d})\end{array}$ & $\alpha$ & $\begin{array}{l}\text { Shape parameter for Gamma } \\
\text { distribution (rainfall block) }\end{array}$ \\
\hline$T_{\text {ovf }}$ & Yearly overflow duration (d) & $\beta$ & Scale parameter for Gamma \\
\hline$V_{\text {ovf }}$ & $\begin{array}{l}\text { Yearly overflow volume } \\
\left(\mathrm{m}^{3}\right)\end{array}$ & & distribution (rainfall block) \\
\hline$V_{\mathrm{r}}$ & $\begin{array}{l}\text { Volume of reservoir }\left(\mathrm{m}^{3}\right) \\
\text { (transport block) }\end{array}$ & & \\
\hline
\end{tabular}




\section{ABSTRACT}

This paper aims at developing a benchmark simulation model to evaluate control strategies for the urban catchment and sewer network. Various modules describing wastewater generation in the catchment, its subsequent transport and storage in the sewer system are presented. Global/local overflow based evaluation criteria describing the cumulative and acute effects are presented. Simulation results show that the proposed set of models is capable of generating daily, weekly and seasonal variations as well as describing the effect of rain events on wastewater characteristics. Two sets of case studies explaining possible applications of the proposed model for evaluation of: 1) Control strategies; and, 2) System modifications, are provided. The proposed framework is specifically designed to allow for easy development and comparison of multiple control possibilities and integration with existing/standard wastewater treatment models (Activated Sludge Models) to finally promote integrated assessment of urban wastewater systems.

\section{KEYWORDS}

Benchmark simulation models; Combined sewer overflows; Integrated control; System-wide evaluation; Urban drainage models

\section{SOFTWARE AVAILABILITY}

\section{Name of the software:}

BSMsewer

\section{Developers:}

R. Saagi, X. Flores-Alsina, G. Fu, L., D. Butler, K.V. Gernaey, U. Jeppsson

\section{Programming language:}

Matlab 13.0

Software availability: The source code for the catchment $\&$ sewer model can be obtained for free. Contact Dr Ulf Jeppsson. Division of Industrial Electrical Engineering and Automation (IEA), Lund University, Box 118, SE-221 00 Lund, Sweden. 


\section{INTRODUCTION}

It has become increasingly clear that wastewater treatment plants (WWTPs) are strongly interconnected to other elements (sewer network, receiving media) within the urban wastewater system (UWS) and the evaluation of WWTP control strategies should be tackled in a more holistic manner (Rauch et al., 2002; Bach et al., 2014). For this reason, there is a need to move "outside the fence" of the WWTP and develop integrated tools for model-based evaluation and control of the UWS (Benedetti et al., 2013). This goal has inspired a large number of scientific contributions that attempt to investigate different aspects of integrated modelling. For example, Benedetti et al. (2004) and Vanrolleghem et al. (2005) tackled important issues such as model integration and model compatibility. Another important aspect has been model complexity reduction to allow for long term simulations (Erbe and Schütze, 2005; Fu et al., 2009a). The latter and the increase in computational power promoted the use of Monte Carlo simulations and the study of input uncertainty propagation through the model either during the model development process or during model use (e.g. Astaraie-Imani et al., 2012; Benedetti et al., 2008; Benedetti et al., 2010; Freni et al., 2011; Fu et al., 2009b). Long term simulations can be conducted as well, including the study of integrated control (e.g. Fu and Butler, 2012; Weijers et al., 2012). Finally, studies of the fate of particular compounds such as sulfur compounds (Jiang et al., 2010), greenhouse gas emissions (Guo et al., 2012) and micro-pollutants (Vezzaro et al., 2014; Snip et al., 2014) were also performed.

One of the major areas of application for integrated models is control. Integrated control has been studied for some years and the main benefits of using such an approach are demonstrated in several studies (e.g. Harremöes et al., 1994; Schütze et al., 2002; Vanrolleghem et al., 2005; Langeveld et al., 2013). With the future clearly pointing towards integrated management of the UWS, the need for development of efficient integrated control strategies is growing. In this context, we believe that a benchmarking tool can be extremely beneficial to develop and test control strategies in the UWS. Within sewer systems, Borsányi et al. (2008) conducted a benchmarking study using real-time control strategies applied to two virtual sewer systems. In the WWTP community, benchmarking control strategies has been very successful. Benchmark Simulation Models (BSM1, BSM1-LT and BSM 2) and associated spin-off products (influent generator, ADM1 implementation, sensor models, evaluation criteria etc.) have demonstrated to be valuable tools in the field of WWTP optimization and have been widely used in both industry and academia (Gernaey et al., 2014). Nevertheless, there is a lack of benchmarking tools that allow objective comparison of control strategies in urban catchments and sewer systems. Therefore: 1) Rigorous development/evaluation of control strategies in the WWTP (Gernaey et al., 2014) is based on influent generators (Gernaey et al., 2011; FloresAlsina et al., 2014; Martin and Vanrolleghem, 2014), and such influent generators are not suitable for modelling control strategies upstream of the WWTP; and, 2) In many cases, integrated UWS control strategies cannot be developed and evaluated on a single simulation platform. 
The objective of this paper is to develop a catchment and sewer network model to benchmark control strategies. The catchment model reproduces the generation of wastewater through the combination of four different sub-models (Domestic (DOM), Industrial (IND), Stormwater ( $S W)$ and Infiltration to sewers (INF)). The sewer model describes wastewater transport (TRANSPORT) as well as the sudden increase of particulates during the beginning of a rain event following a period of drought (FIRST FLUSH) and the retention of wastewater (especially during rain events) using storage tanks to avoid combined sewer overflows (STORAGE). A set of evaluation criteria are used to assess the overflow discharged into the receiving waters. The criteria can be applied for a specific overflow location (Local) or for the entire system (Global). The criteria can be further classified into those describing: 1) cumulative effects; and, 2) acute effects on the receiving water system. As a receiving water model is not used in this study, these criteria are only indirect indicators of the effect of overflow discharges on river systems. Additionally, case studies demonstrating the possible applications of the tool for analyzing the impact of: 1) local/global control strategies; and, 2) system modifications, are presented and discussed in detail. The proposed framework is specifically designed to allow for development and comparison of multiple control strategies, and allows easy interfacing with existing wastewater treatment (benchmark) models to finally promote integrated assessment of catchment, sewer network and WWTP performance.

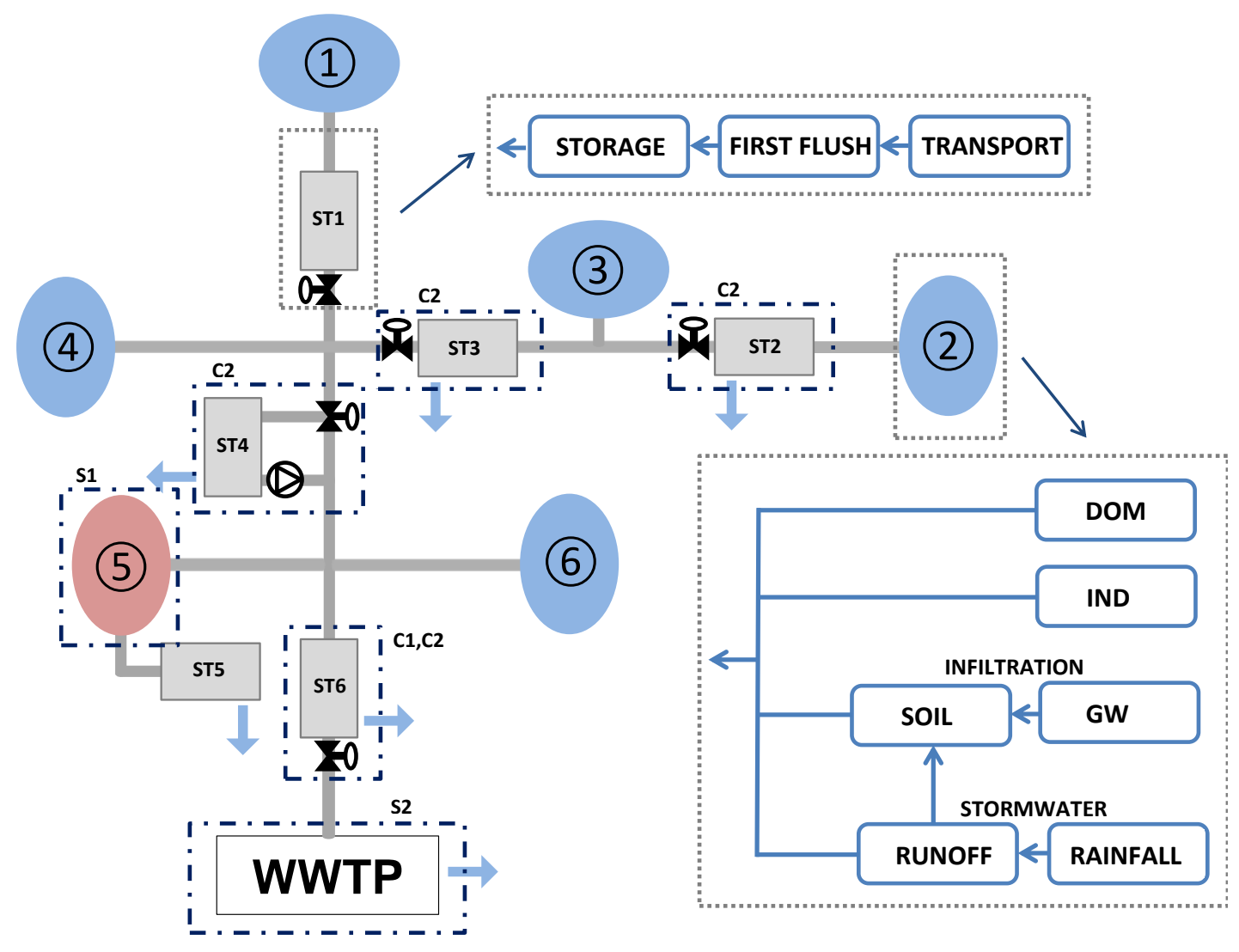

Figure 1: Catchment and sewer BSM layout indicating various sub-catchments (1), (2), (3), (4), (5), (6) represent SC1, SC2, SC3, SC4, SC5 and SC6 respectively), storage tanks (ST1,ST2, ST3, ST4, ST5, ST6) and control elements. 
Overflows are assumed to enter a receiving water (not modelled here). A snapshot of the underlying blocks for the CATCHMENT and SEWER models is presented. The locations for control strategies $(\mathrm{C} 1, \mathrm{C} 2)$ and structural modifications (S1, S2) are highlighted. DOM, IND, GW stand for domestic, industrial and groundwater respectively.

\section{SYSTEM CHARACTERISTICS AND GENERAL MODEL DESCRIPTION}

A hypothetical system with a similar structure as the catchment described in ATV A 128 (ATV, 1992) is used as a case study. Figure 1 illustrates the catchment configuration and its main characteristics. The total catchment area $\left(A_{\mathrm{c}}\right)$ is 540 hectares and comprises 80,000 population equivalents $\left(P E_{\mathrm{c}}\right)$. Dry weather flow is scaled up to be similar to the BSM2 influent characteristics $\left(18,500 \mathrm{~m}^{3} / \mathrm{d}\right)($ Gernaey et al., 2014). The three main contributors to dry weather flow are: 1) domestic sources with a daily average flow (DAF) of 12,000 $\mathrm{m}^{3} / \mathrm{d}$; 2) industrial contribution with a DAF of $2,500 \mathrm{~m}^{3} / \mathrm{d}$; and, 3) infiltration to sewers which corresponds to $25 \%$ of the dry weather flow.

Table 1: System characteristics for the catchment, storage tanks and sewer network.

\begin{tabular}{|c|c|c|c|c|c|}
\hline \multirow[t]{2}{*}{ Sub-catchment (SC) } & \multirow[t]{2}{*}{ Area (ha) } & \multirow[t]{2}{*}{ PE } & \multicolumn{2}{|c|}{ DWF (m²/day) } & \multirow[t]{2}{*}{ Storage volume $\left(\mathrm{m}^{3}\right)$} \\
\hline & & & $D O M$ & IND & \\
\hline 1 & 99 & 15,920 & 2,390 & & 5500 \\
\hline 2 & 21 & 3,920 & 590 & 2,500 & 1000 \\
\hline 3 & 29 & 2,960 & 440 & & 2000 \\
\hline 4 & 71 & 9,600 & 1,440 & & 4000 \\
\hline 5 & 71 & 7,840 & 1,180 & & 4000 \\
\hline 6 & 249 & 39,760 & 5,960 & & 15000 \\
\hline Total & 540 & 80,000 & 12,000 & 2,500 & 31,500 \\
\hline
\end{tabular}

The system under study is comprised of six sub-catchments (SC1,.., SC6) with different areas (A1,.., A6) and population densities (PE1,.., PE6) (see Table 1). All the defined SCs are considered to be domestic except SC2, which has both domestic and industrial contributions. SC1, SC2, SC3, SC4 and SC6 are connected to a combined sewer system whereas SC5 has a separate sewer system. The proposed catchment also has six storage structures (five on-line pass-through tanks and one off-line bypass tank) (see Figure 9 for additional details). Finally, it should be mentioned that the entire catchment is connected to a WWTP, which has the same layout/characteristics as the BSM2 plant-wide model (Jeppsson et al., 2007). Sewer overflows and WWTP effluents are discharged at various locations into the receiving waters as depicted in Figure 1. It should be noted that the current study does not include the river system.

\section{CATCHMENT MODEL}

The catchment model is largely inspired by the BSM2 dynamic influent pollutant disturbance scenario generator (DIPDSG) (Gernaey et al., 2011) and uses many of its salient model blocks for simulating the dynamics of flow rate and pollutant load generation. The generation of wastewater at each sub-catchment $\left(\mathrm{SC}_{\mathrm{i}}\right)$ is achieved by combining the contributions from: 1) domestic $\left.\left(D O M_{i}\right) ; 2\right)$ industry $\left.\left(\operatorname{IND} D_{i}\right) ; 3\right)$ infiltration to sewers $\left(I N F_{i}\right)$; and, 4) stormwater $\left(S W_{i}\right)$. The pollutants considered are chemical oxygen demand (COD), ammonia $\left(\mathrm{NH}_{4}{ }^{+}\right)$, nitrate $\left(\mathrm{NO}_{3}{ }^{-}\right)$and phosphate $\left(\mathrm{PO}_{4}{ }^{3-}\right)$. COD is further subdivided into 
$\mathrm{COD}_{\text {sol }}$ (soluble COD) and $\mathrm{COD}_{\text {part }}$ (particulate COD). All pollutants are represented as loads $(\mathrm{kg} / \mathrm{d})$. The flow rate is expressed in $\mathrm{m}^{3} / \mathrm{d}$ units. In the catchment model, the subscript "i" denotes various parameters and model state variables for each sub-catchment.

\subsection{Domestic (DOM)}

In the proposed approach, the domestic $(D O M)$ sub-model contributes to the influent flow rate/pollutant dynamics by diurnal variations, a weekend effect and a holiday effect. This is achieved by combining three user-defined data files containing: 1) a normalized daily profile; 2) a weekly pattern including the weekend effect; and, 3) a holiday effect. The generated time series is then multiplied by the flow rate/pollution load per population equivalent $\left(\mathrm{m}^{3} / \mathrm{PE}\right.$.day, $\mathrm{kg} / \mathrm{PE}$.day) and the number of person equivalents in the specific subcatchment $\left(P E_{i}\right)$ (for default values see Gernaey et al., 2011; Flores-Alsina et al., 2014; Snip et al., 2014).

- Normalized daily profile: The daily flow rate/pollution profile represents a general behaviour with a morning peak, an evening peak and a late night/mid-day minima (Figure 2a). It is important to notice that the particulate profile slightly lags behind that of the soluble pollutants. This effect is introduced to account for the slower transportation rate of particulates.

- Weekly profile: A drop in the flow-rate/pollutant generation during weekends is modelled using a uniform value during weekdays and a lower fraction during the weekends (Figure 2b). This corresponds to an $8 \%$ and $12 \%$ drop in flow rate on Saturdays and Sundays, respectively. For pollution loads, a higher reduction factor is applied (12\% on Saturdays and $16 \%$ on Sundays).

- Yearly profile (holiday effect): A similar approach as defined above is used to account for the yearly profile. The holiday period ( 3 week period during July-August) represents a $25 \%$ reduction of the flow rate/pollution load during the first two weeks and a $12 \%$ decrease during the third week (Figure 2c).

Zero-mean white noise can be added to these inputs. It is up to the model user to decide whether or not to include random noise. The purpose of including noise is two-fold: 1) To avoid having exactly the same profiles for pollutants/flow rates on different days of the week; and, 2) To avoid an exact correlation (correlation coefficient=1) between state variables in the catchment model and also ASM state variables (see Gernaey et al., 2011; Snip et al., 2014 for further information). This however does not remove the correlation completely (e.g. flow rate and soluble pollutant profiles are still correlated)..
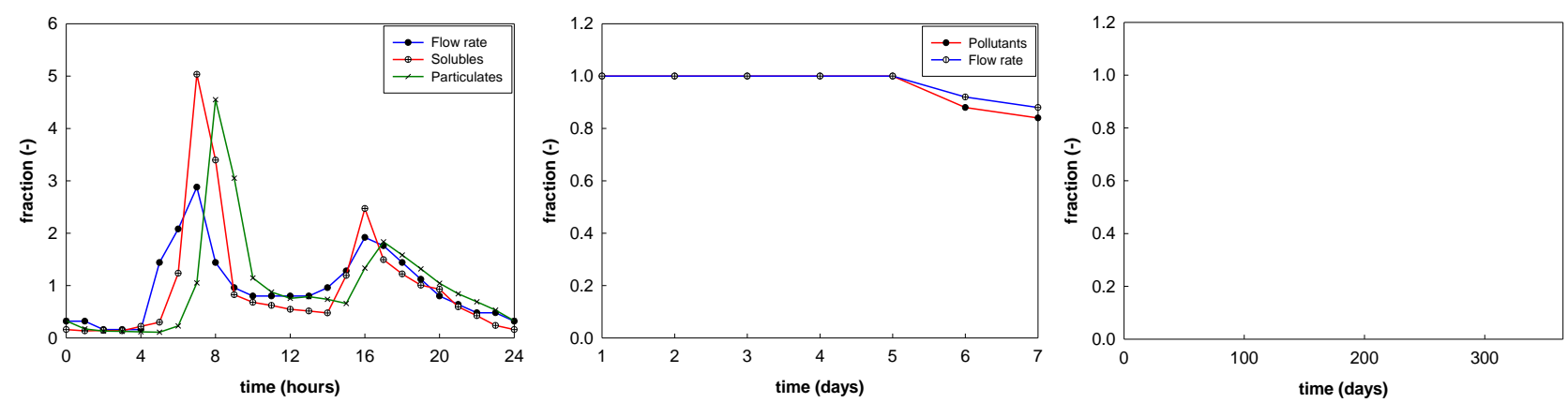
Figure 2: Diurnal variation in pollutant loads and flow rate (a). Weekly variation with two different profiles (red = pollutants, blue $=$ flow rate) (b) and yearly profile (starting first week of July) with similar dynamics for pollutants and flow rate (c). 


\subsection{Industrial (IND)}

The industrial (IND) contribution to the influent flow rate/pollutant load is generated similarly to the DOM sub-model. The industry model block is also based on user-defined files describing weekly and yearly effects. Again, the dynamic pattern is generated by sampling in a cyclic manner from source files and then multiplied by the average daily wastewater/pollution generation from the industry $\left(\mathrm{m}^{3} / \mathrm{day}, \mathrm{kg} /\right.$ day) (see Gernaey et al. (2011) for additional information/default values). In the case demonstrated in this paper, these values only apply to $\mathrm{SC}_{2}$ as it is the only sub-catchment with an industrial contribution. Adding zero mean white noise adds realism to the industrial wastewater profiles.

- Weekly profile: As can be seen in Figure 3, the variations in the industry pollutant fluxes are less extreme than the variations of the domestic pollutant fluxes. Also, when the industrial particulate pollutant flux is compared to the industrial wastewater flow rate, the particulate pollutant flux shows a four hour time delay to account for the slower transport of particulates. The Friday afternoon effect is also illustrated in Figure 3a, during which the pollutant fluxes are doubled, assuming to be the consequence of industrial cleaning. During the weekend, the industrial flow and pollutant fluxes are considerably lower compared to weekdays (60\% decrease of the flux on Saturdays and $80 \%$ decrease on Sundays).

- Yearly profile: Two holiday periods marked with lower wastewater generation are modelled (Figure 3b). Hence, the industrial wastewater production is reduced by $70 \%$ during the summer holidays and $80 \%$ during the Christmas period to simulate the shutdown of industrial activities during these periods.

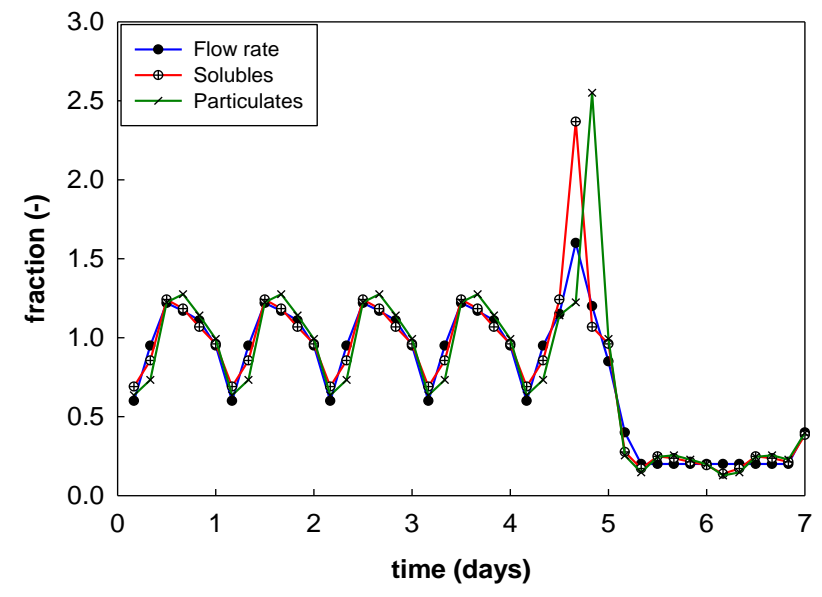

a

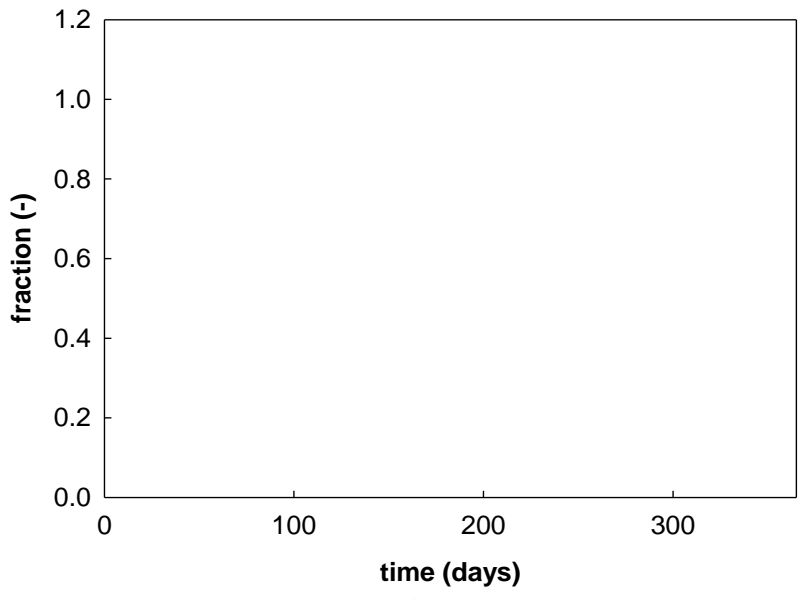

b

Figure 3: Dynamics of industrial dry weather pollutant and flow rate generation with weekly (a) and yearly (b) variations. The yearly profile begins in the first week of July.(For simplicity, we assume that the first day of july is a Monday). 


\subsection{Stormwater (SW)}

The stormwater (SW) sub-model is comprised of two different elements: a rainfall generator block (rainfall), which characterizes the intensity and duration of precipitation and a runoff contribution block (runoff), which generates the flow rate/pollution load corresponding to the rain events.

\subsubsection{Rainfall generator block (rainfall)}

The rainfall block can be used in two different ways. Firstly, rainfall data described as intensity $(\mathrm{mm} / \mathrm{h})$ can be used as a model input. A second option is based on a stochastic rainfall generation approach (Richardson. 1981). The latter approach is used in this paper. The implementation in this study is inspired by the rainfall generator proposed by Talebizadeh et al. (2016). The representation of rainfall is described mathematically using a two state Markov chain model. Two different states are defined representing dry (DRY) and wet (WET) weather periods. The transition between states is defined by a transition probability matrix (P) (see Equation 1), which is estimated from historic data. In the matrix $\mathrm{P}$, the value $P_{\mathrm{d} \mid \mathrm{w}}$ represents the probability for the next period to be wet given that the current period is dry and vice-versa for $P_{\mathrm{w} \mid \mathrm{d}}$. The other probability values can also be interpreted in a similar fashion. Each period lasts for 15 minutes. These probabilities change on a monthly basis to better describe the seasonal variation in precipitation. A key property for the Markov chain is that it does not have any memory. Therefore, the state of a system for the next time step $(t+1)$ is determined solely by its state in the current time step $(\mathrm{t})$.

$P=\left[\begin{array}{ll}P_{\mathrm{d} \mid \mathrm{d}} & P_{\mathrm{d} \mid \mathrm{w}} \\ P_{\mathrm{w} \mid \mathrm{d}} & P_{\mathrm{w} \mid \mathrm{w}}\end{array}\right]$

Finally, a gamma distribution (Equations $2 \&$ 3) (Buishand, 1978) determines the rainfall intensity for the WET periods that are generated using the Markov chain. Parameters $\alpha$ and $\beta$, called the shape and scale parameters, are determined by fitting the historic rainfall data to a gamma distribution.

$f(x)=\frac{\left(\frac{x}{\beta}\right)^{\alpha-1} e^{-\frac{x}{\beta}}}{\beta \Gamma(\alpha)}$

$\Gamma(\alpha)=\int_{0}^{\infty} e^{-t} t^{\alpha-1} \mathrm{~d} t$

Figure 4 presents the (synthetic) yearly rainfall data generated using the stochastic rainfall generator described above. The total annual rainfall from data and model is $721 \mathrm{~mm}$ and $738 \mathrm{~mm}$, respectively. Simulation results show that the model produces similar monthly variations and annual rainfall but there is room for improvement when describing high intensity rainfall events. This is due to the fact that such high rainfall events are very rare and hence the probability of such an event being reproduced by the gamma distribution is low. It is important to highlight that the approach presented herein is an empirical one and is purely an engineering attempt. A detailed analysis to validate the rainfall generator in terms of its ability to reproduce the statistical properties of the historic rainfall time series is not performed (Ward and Robinson, 
2000). Only visual inspection is used to validate the model. Also, the model has various limitations. Two of the main limitations are: 1) Transition between wet/dry states is only a function of the previous period (which can be less than a day). It does not consider the effect of previous days; and, 2) Rainfall intensity during each period is independent of the intensity in the previous periods. Owing to these limitations, users are suggested to exercise caution while using this model for their particular catchments. Nevertheless, we believe that the tool is useful to simulate various rainfall patterns for evaluating control strategies on an UWS scale. It can be easily adapted to simulate high/low intensity and long/short duration rainfalls by varying the transition probabilities and the parameters of the gamma distribution.

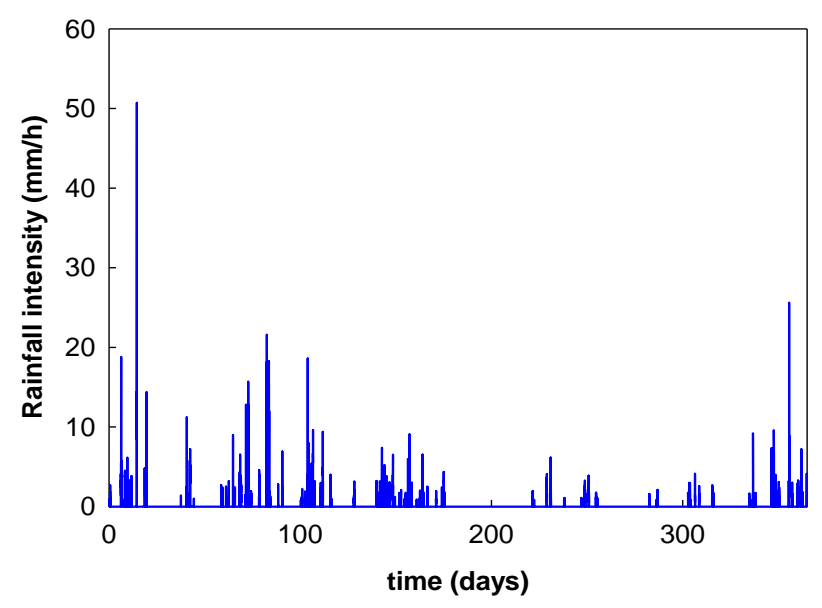

a

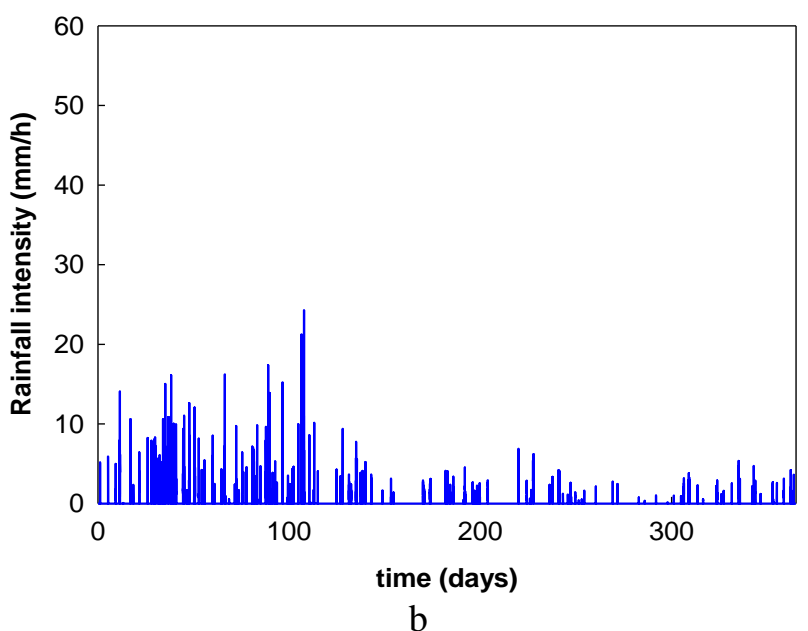

$\mathrm{b}$

Figure 4: Rainfall intensity time series from data (a) and the one generated using the model (b) for a period of 1 year. The time series begins in the first week of July.

\subsubsection{Runoff contribution block (runoff)}

The runoff block is used to convert the rainfall intensities $(\mathrm{mm} / \mathrm{h})$ into surface runoff $\left(\mathrm{m}^{3} / \mathrm{d}\right)$. It also accounts for the (soluble/particulate) pollution contribution from each sub-catchment surface to the sewer system.

- The flow rate runoff block uses a dimensionless rainfall runoff coefficient $\left(r r c_{i}\right)$ to represent various continuous losses taking place within the sub-catchment. The impervious area $\left(A_{\text {imp }, i}\right)$ is determined by the parameter $\varphi_{i}$ representing the impervious fraction of the sub-catchment surface. Rain falling on impervious areas is multiplied by the $r r c_{i}$ to generate the runoff which is then passed through a linear reservoir model to simulate the delay and attenuation typically observed in urban catchments. A similar approach is used in the sewer system (see Section 4).

- The soluble pollution contribution (sol-poll runoff) (Figure 5a) is calculated assuming a constant pollutant concentration during rain events. These values are also known as event mean concentrations (EMC) and may vary depending on the catchment characteristics and the rain event. EMC values for soluble COD $\left(9 \mathrm{~g} / \mathrm{m}^{3}\right)$ and ammonium $\left(0.56 \mathrm{~g} / \mathrm{m}^{3}\right)$ are based on Butler and Davies (2011). EMC values for nitrate and phosphate are assumed to be zero. These concentrations are then multiplied by the flow rate $\left(\mathrm{m}^{3} / \mathrm{d}\right)$ obtained from the flow rate runoff block to generate pollutant 
loads $(\mathrm{kg} / \mathrm{d})$. Due to this simplified approach of assuming constant concentration for all rain events, the model cannot simulate the influence of antecedent dry days/rain on the soluble pollutant concentration.

- The last element is the particulate pollution contribution (part-poll runoff). This model block is based on an accumulation and washoff approach (Butler and Davies, 2011) (Figure 5b). There is an accumulation of particulate $\mathrm{COD}\left(\mathrm{COD}_{\text {part }}\right)$ during dry weather periods until a maximum threshold is reached. During rain events, the accumulated pollutant is washed off depending on the intensity of the rain event and the amount of pollutant accumulated. Equation 4 describes the variation of the mass of pollutant on the sub-catchment surface $\left(M_{\mathrm{s}, i}\right)(\mathrm{kg})$. The parameter $\left(a_{i}\right)(\mathrm{kg} / \mathrm{ha} . \mathrm{d})$ defines the rate of accumulation of the pollutant and $\left(A_{i}\right)$ is the sub-catchment area. In order to avoid pollutant mass reaching large values, a removal rate characterized by the parameter $b_{i}$ (decay rate constant $(1 / d))$ is used. Hence, during a long dry period, a maximum pollutant mass is reached and no further accumulation takes place. During a rain event, the pollutant is washed out at a rate determined by the washoff constant $\left(w_{i}\right)\left(\mathrm{mm}^{-1}\right)$ and rainfall intensity $\left(i_{\text {rain }}\right)(\mathrm{mm} / \mathrm{h})$ and the available mass on the catchment surface $\left(M_{\mathrm{s}, i}\right)$. A conversion factor (24) is used to convert the resulting washoff load from $\mathrm{kg} / \mathrm{h}$ to $\mathrm{kg} / \mathrm{d}$. From Figure $5 \mathrm{~b}$, it can be seen that the parameters are aggressively tuned leading to consecutive washoff of particulates during day 516. The results presented correspond to the output of the accumulation and washoff block. There are a series of reservoirs (sewer network) that attenuate the peak values before the pollutant load reaches CSOs/WWTP. In the absence of such tuning, the increase in particulate load is not noticeable at CSOs/WWTP.

$\frac{\mathrm{d} M_{\mathrm{s}, i}}{\mathrm{~d} t}=a_{\mathrm{i}} A_{\mathrm{i}}-b_{\mathrm{i}} M_{\mathrm{s}, \mathrm{i}}-24 w_{\mathrm{i}} i_{\text {rain }} M_{\mathrm{s}, \mathrm{i}}$

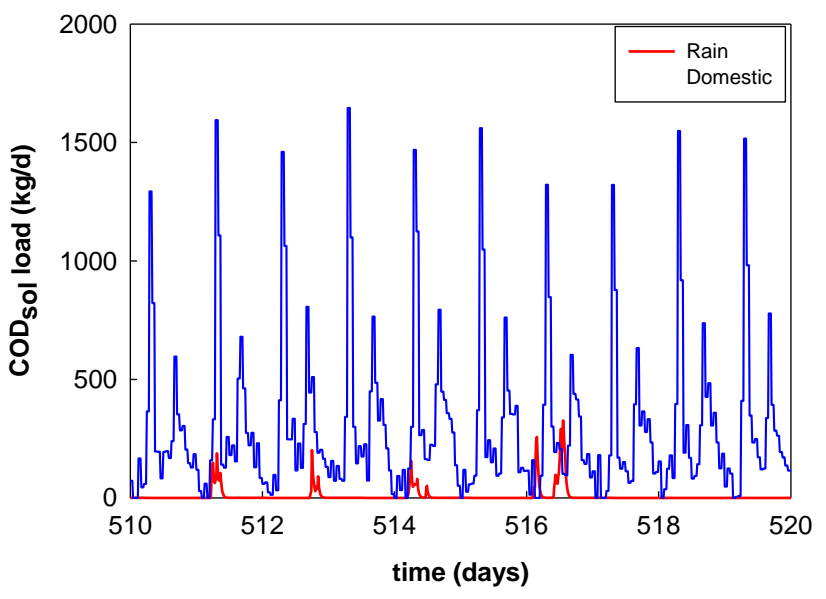

a

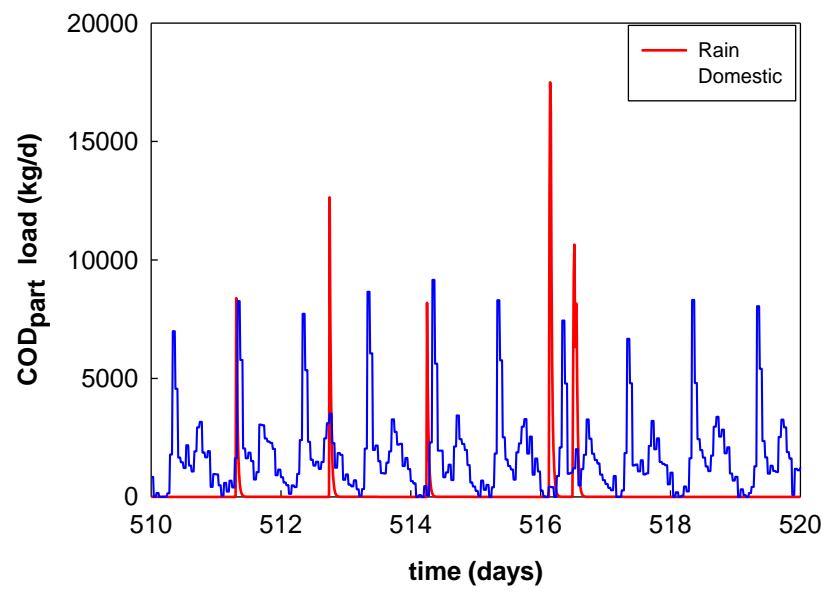

b

Figure 5: Effect of EMC during rainfall on soluble pollutant $\left(\mathrm{COD}_{\mathrm{sol}}\right)(\mathrm{a})$, and effect of the accumulation and washoff model on $\mathrm{COD}_{\text {part }}(\mathrm{b})$. 


\subsection{Infiltration to sewers (INF)}

The infiltration to sewers (INF) sub-model is comprised of two main elements. Firstly, a groundwater block (groundwater) and secondly a soil block (soil) (Gernaey et al., 2011). The groundwater block describes changes in the amount of infiltration attributed to variations in the groundwater level over the year (Figure 6). Seasonal groundwater inflow is modelled as a sine wave with a yearly frequency. The groundwater inflow to the model is at its lowest during the dry period and at its highest during the rainy period of the year. Additional details can be found in Gernaey et al. (2011). The (total) annual mean groundwater inflow ( $G W_{\text {in }}$ ) for the entire catchment is $7,100 \mathrm{~m}^{3} / \mathrm{d}$ and the amplitude of variation (Infamp) is $25 \%$. Based on the area of each sub-catchment, a mean groundwater inflow is defined as a fraction of the annual average for the entire catchment $\left(G W_{\mathrm{in}, \mathrm{i}}\right)$.

The soil block is described using a variable volume tank model for each sub-catchment. It is used to represent the assumed volume of water stored in the soil $\left(V_{\text {soil, }}\right)$. Parameters for the soil model are: $A_{\text {soil,i }}$ (the surface area of the variable volume tank) which is the pervious area of the sub-catchment $\left(\varphi \cdot A_{\mathrm{i}}\right), h_{\max , \mathrm{i}}$ (the maximum level in the tank), $h_{\mathrm{inv}, \mathrm{i}}$ (the invert level, i.e. the maximum water level in the groundwater storage tank that will not cause infiltration, corresponding to the bottom level of the sewer pipes). $R D I_{\mathrm{in}, \mathrm{i}}$ (rainfall dependent inflow) is the runoff generated due to rain from pervious areas (see Section 3.3). $K_{\text {soil, }}$ is defined as the soil permeability. $R D I_{\mathrm{in}, \mathrm{i}}$ is limited by the permeability of the soil (maximum $R D I_{\mathrm{in}, \mathrm{i}}$ equals $K_{\text {soil, } \mathrm{i}} A_{\text {soil, } \mathrm{i}}$ ). Any excess rainfall dependent inflow reaches the sewer system. Infiltration to sewers $\left(Q_{\text {inf,i }}\right)$ from the soil (soil) block is modelled by the parameter $K_{\mathrm{inf,i}}$ (a measure of the quality of sewer pipes). Similarly, infiltration to groundwater $\left(Q_{\mathrm{GW}, \mathrm{i}}\right)$ is determined using the parameter $K_{\mathrm{down}, \mathrm{i}}$ (parameter to adjust the flow rate to the downstream aquifers). Equation 5 represents the volume balance for the soil model. Equation 6 elaborates on the volume balance in the soil block based on the relationship between various outflows and the storage height $\left(h_{\text {soili, }}\right)$. In order to keep the model simple, the case where wastewater from the sewer system reaches the groundwater (exfiltration) (Rutsch et al., 2006) is not considered here.

$\frac{\mathrm{d} V_{\text {soil, } \mathrm{i}}}{\mathrm{d} t}=G W_{\mathrm{in}, \mathrm{i}}+R D I_{\mathrm{in,i}}-Q_{\mathrm{inf}, \mathrm{i}}-Q_{\mathrm{GW}, \mathrm{i}}$

$\frac{A_{\text {soil }, \mathrm{i}} \mathrm{d} h_{\text {soil }, \mathrm{i}}}{\mathrm{d} t}=G W_{\mathrm{in}, \mathrm{i}}+R D I_{\mathrm{in}, \mathrm{i}}-K_{\mathrm{inf,i}} \sqrt{h_{\mathrm{soil}, \mathrm{i}}-h_{\mathrm{inv}, \mathrm{i}}}-K_{\mathrm{down}, \mathrm{i}} h_{\mathrm{soil}, \mathrm{i}}$ Eq. 6 


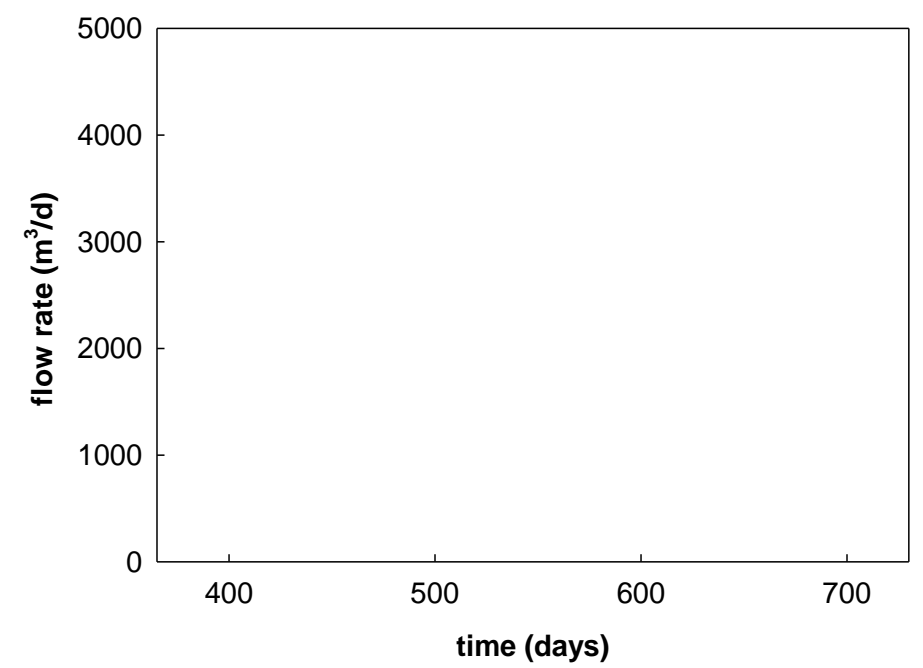

Figure 6: Infiltration to sewers from $\mathrm{SC}_{1}$ depicting the annual variations and also rainfall dependent variations.

\section{SEWER NETWORK MODEL}

The sewer model is comprised of three different elements: 1) a transport sub-model (TRANSPORT) to describe the effect of the sewer system on both flow rate and pollutants; 2) a first flush sub-model (FIRST FLUSH) mimicking the sudden increase of particulates at the beginning of rain events following a period of drought; and, 3) different types of storage tank sub-models (STORAGE) acting as buffers to prevent discharge of rainwater into rivers during rain events. These three sub-models are used repetitively at various locations. Biological transformations within the sewer system (Huisman, 2001; Snip et al., 2014) are not considered in the model.

\subsection{Sewer transport (TRANSPORT)}

Flow and pollution transport within the sewer system is modelled using completely mixed tanks with varying volumes (Viessman et al., 1989). Equation 7 represents the mass balance for volume $\left(V_{\mathrm{r}}\right)\left(\mathrm{m}^{3}\right)$ of the reservoir where $Q_{\mathrm{in,r}}$ and $Q_{\mathrm{out}, \mathrm{r}}$ are input and output flow rates $\left(\mathrm{m}^{3} / \mathrm{d}\right)$, respectively, for each reservoir block. The outflow is related to the volume based on a residence time constant $\left(K_{\mathrm{r}}\right)(\mathrm{d})$.

$\frac{\mathrm{d} V_{\mathrm{r}}}{\mathrm{d} t}=Q_{\text {in, } \mathrm{r}}-Q_{\text {out }, \mathrm{r}} ; Q_{\text {out }, \mathrm{r}}=\frac{1}{K_{\mathrm{r}}} V_{\mathrm{r}}$

$\frac{\mathrm{d} M_{\mathrm{r}}}{\mathrm{d} t}=X_{\mathrm{in}, \mathrm{r}}-X_{\text {out }, \mathrm{r}} ; X_{\text {out }, \mathrm{r}}=\frac{1}{K_{\mathrm{r}}} M_{\mathrm{r}}$

Similarly, in Equation 8, $M_{\mathrm{r}}$ is the pollutant mass $(\mathrm{kg}) . X_{\mathrm{in}, \mathrm{r}}, X_{\mathrm{out}, \mathrm{r}}$ are the input and output loads $(\mathrm{kg} / \mathrm{d})$. Figure 7 shows the effect of the parameter $K_{\mathrm{r}}$ on the outflow. With longer residence time, a larger sewer system is simulated. Longer sewer lengths can also be simulated by connecting a number of such reservoirs in series. The number of reservoirs in series $\left(n_{\mathrm{r}}\right)$ depends on the length of the sewer system. The larger the catchment, the higher is the number of reservoirs in series. In this particular study, $K_{\mathrm{r}}$ and $n_{\mathrm{r}}$ values are 
estimated assuming a total sewer length of $1 \mathrm{~km}$ per 15 ha of catchment area. These values are in the same range as some Scandinavian cities ( $2 \mathrm{~km}$ per $15 \mathrm{ha}$ ) (VASYO 2015a;b).

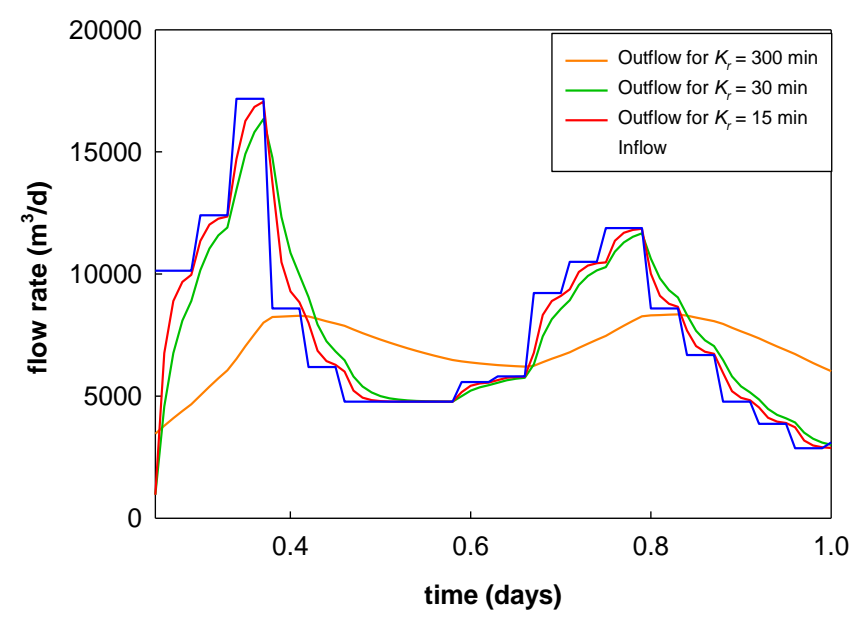

a

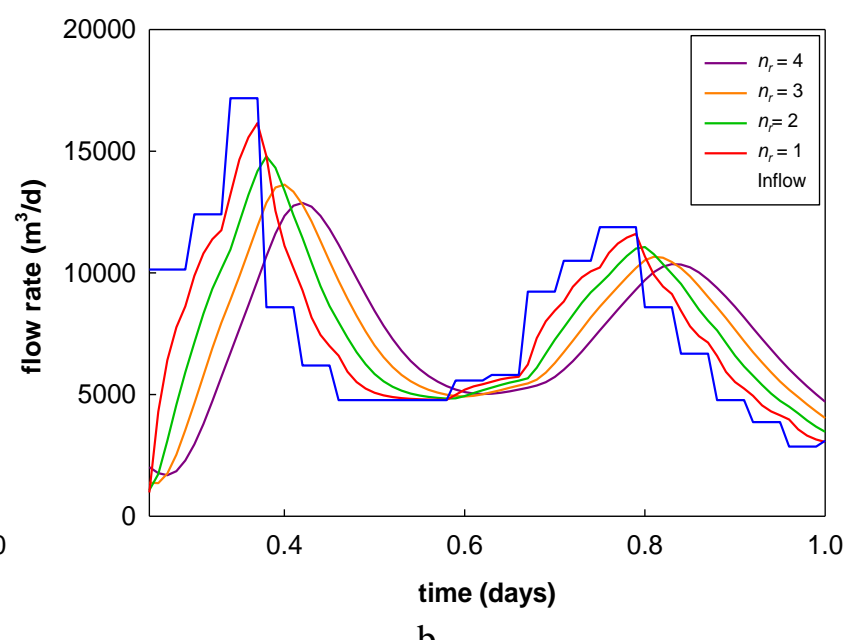

b

Figure 7: Reservoir model used for the sewer network. Effect of different residencence time constants $\left(K_{\mathrm{r}}\right)$ for a given inflow (a). Variations in the outflow based on the number of such reservoirs $\left(n_{\mathrm{r}}\right)$ in series $(\mathrm{b})$.

\subsection{First flush of particulates (FIRST FLUSH)}

The FIRST FLUSH sub-model mimics the sudden increase of particulates that have been accumulated within the sewer during dry weather periods. The model relies on the assumption that only a part of the particulate material can settle in the sewer system (FFfraction) and be accumulated until a flow rate threshold is reached. The accumulated particulates are washed out during rain events. The extent of washoff depends on the intensity of the flow rate. Equation 9 describes the accumulation of particulates $\left(\mathrm{COD}_{\text {part }}\right)\left(M_{\mathrm{ff}}\right)$ in the sewer as a function of the flux of solids entering $\left(X_{\mathrm{in}, \mathrm{ff}}\right)$ and leaving $\left(X_{\mathrm{ou}, \mathrm{ff}}\right)$ the system. $Q_{\mathrm{in}, \mathrm{ff}}$ represents the influent flow rate $\left(\mathrm{m}^{3} / \mathrm{d}\right) . M_{\max , \mathrm{ff}}(\mathrm{kg})$ is the maximum amount of particulates that can be stored in the sewer system. $Q_{\text {lim,ff }}\left(\mathrm{m}^{3} / \mathrm{d}\right)$ is the flow rate limit triggering the first flush effect. $F F\left(\mathrm{~d}^{-1}\right)$ and $n_{\mathrm{ff}}(-)$ are adjustable parameters to tune the desired strength of the first flush effect. The first term in the equation represents accumulation of particulates. Particulates accumulate until a maximum mass $M_{\max , \mathrm{ff}}$ is reached. The second term is a Hill function representing the washoff during rain events. At very low $Q_{\text {in,ff }}$ values (dry weather flows), the washoff is negligible. As the inflow increases and reaches $Q_{\text {lim,ff }}$, the particulate washoff increases rapidly.

$\frac{\mathrm{d} M_{\mathrm{ff}}}{\mathrm{dt}}=X_{\mathrm{in}, \mathrm{ff}}\left(1-\frac{M_{\mathrm{ff}}}{M_{\mathrm{max}, \mathrm{ff}}}\right)-\frac{Q_{\mathrm{in}, \mathrm{ff}}^{\mathrm{n}_{\mathrm{ff}}}}{Q_{\text {lim,ff }}^{\mathrm{n}_{\mathrm{ff}}}+Q_{\mathrm{in}, \mathrm{ff}}^{\mathrm{n}_{\mathrm{ff}}}} M_{\mathrm{ff}} F F$

Figure 8 depicts the influence of the FIRST FLUSH model on the particulate pollutant behaviour for the sewer system connected to $\mathrm{SC}_{6}$. When the influent flow rate is higher than the triggering flow rate $\left(Q_{\text {lim,ff }}=\right.$ $\left.29,820 \mathrm{~m}^{3} / \mathrm{d}\right)$ and the sewer is full of sediments $\left(M_{\text {max,ff }}=2,490 \mathrm{~kg}\right)$ there is a sudden increase of $\mathrm{COD}_{\text {part }}$ load in the influent to the WWTP $\left(F F=2,500, n_{\mathrm{ff}}=15\right.$ and FFfraction $\left.=0.25\right)$. A similar over-tuning of parameters (as noticed in accumulation and washoff model (section 3.3.2)) can be noticed in Figure 8. Due to 
the presence of the sewer network, the pollutant peaks get reduced considerably before reaching the CSOs/WWTP. Over-tuning is necessary to compensate for this behaviour.

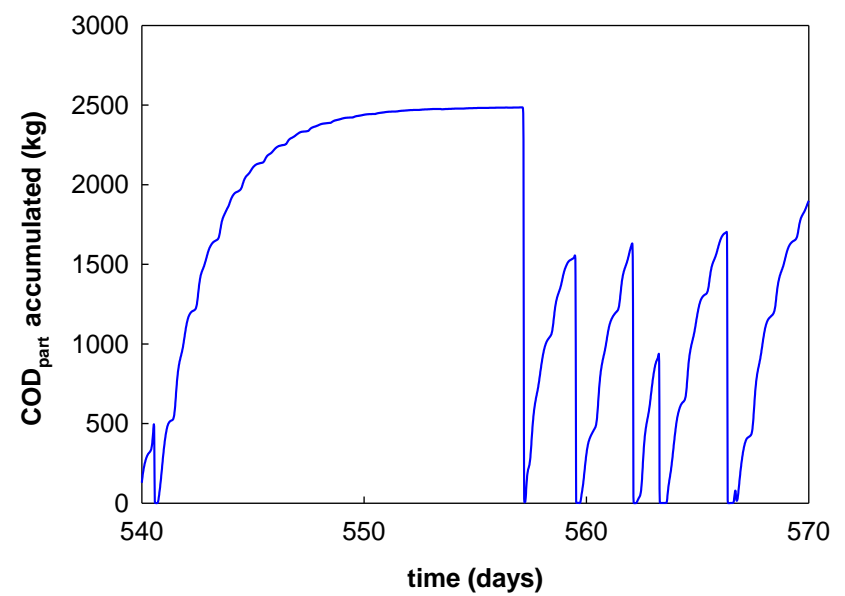

a

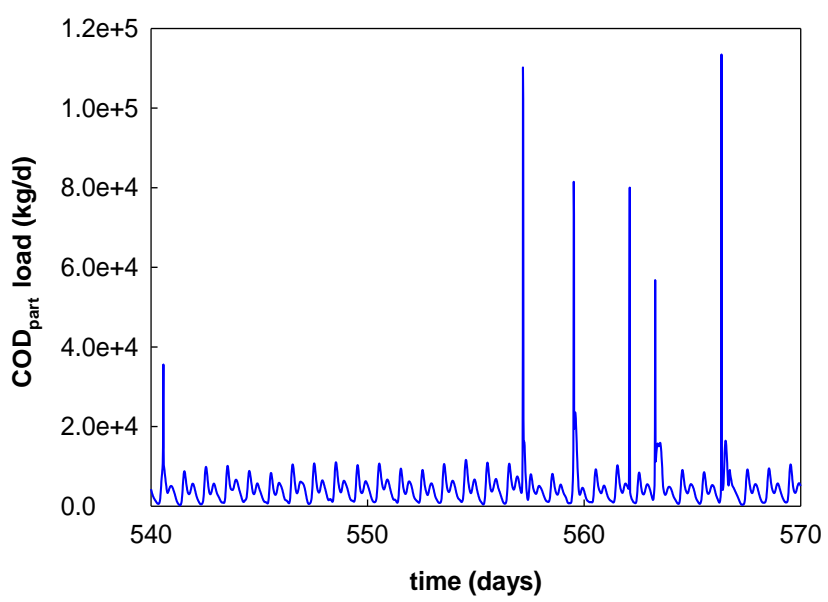

b

Figure 8: Accumulation of $\mathrm{COD}_{\text {part }}$ in the sewer system (a), and the sewer particulate load (blue) (b) .

\subsection{Storage tanks (STORAGE)}

Storage tanks (STs) are the main control elements to regulate the incoming flow to the WWTP and sewer overflows to rivers. The volume of each of these tanks is approximately $60 \mathrm{~m}^{3} / \mathrm{ha}$ of catchment area. In Europe, storage volumes range from $30 \mathrm{~m}^{3} /$ ha to $200 \mathrm{~m}^{3} /$ ha (Schutze et al., 2002). There are four different configurations of the tanks which are mainly classified into on-line and off-line modes (Figure 9).

1. On-line tanks: These tanks are in-line with the sewer network and the storage volume is in use during dry weather as well. The entire dry weather flow passes through the tank and reaches the WWTP. Valves can be used to limit the throttle flow. A valve model with a linear relationship between valve opening and flow rate variation is included.

2. Off-line tanks: These storage tanks are not directly in-line with the sewer network. The sewer pipes have a maximum capacity and any excess flow is directed to the storage tank. In the case of off-line tanks, typically pumps are used to send the stored wastewater back to the sewer system. Therefore, the outflow from the tanks is governed by the pumping rate. Pump flow can either be supplied as an input or as an actuator setting from a controller.

In addition, pass-through and bypass configurations are modelled for both on-line and off-line storage tanks.

1. Pass-through tanks: The overflow weir is located at the end of the storage tank. All the inflow to the storage tank passes through the tank before reaching the outlet or overflowing into the river.

2. Bypass tanks: These are tanks with overflow at the beginning of the storage tank. This is advantageous especially in systems with high first flush effects. For on-line tanks, this highly polluted stormwater reaches the WWTP. Similarly, for off-line tanks, the stored stormwater can later be pumped back to the trunk sewer and from there to the WWTP. 
Only two of the four available configurations are used in the current layout (Figure 1). ST1, ST2, ST3 and ST6 are on-line pass-through tanks while ST4 is an off-line bypass tank.

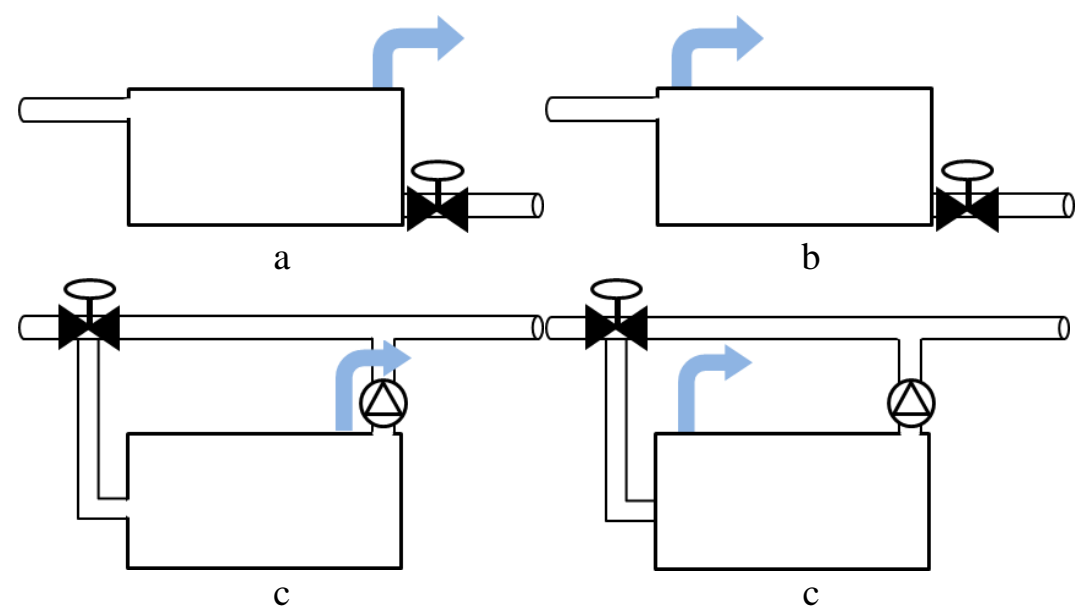

Figure 9: Different configurations of storage tanks: a) on-line pass-through tank; b) on-line bypass tank; c) off-line pass-through tank; d) off-line bypass tank. Pumps and valves are used as flow control elements in off-line and on-line tanks, respectively.

Table 2 summarizes the mass balance and equations used for the previously described storage tanks. $V_{\text {st }}$ is the volume of the tank filled with water and $A_{\text {st }}$ denotes the surface area of the tank. $Q_{\mathrm{in}, \mathrm{st}}$ and $Q_{\text {outst } \mathrm{st}}$ represent the inflow and outflow from the storage tanks. In the case of on-line tanks, $Q_{\text {outst }}$ represents the throttle flow from the tank (Vallet, 2011). For off-line tanks, it is the pumping rate $Q_{\text {pump,st }}$. Overflows are denoted by $Q_{\text {ovf,st }}\left(\right.$ Hager, 2010). $M_{\mathrm{c}, \mathrm{st}}$ denotes the mass of each pollutant (c) and $X_{\mathrm{c}, \mathrm{in}, \mathrm{st}}$ and $X_{\mathrm{c}, \mathrm{out}, \mathrm{st}}$ represent the corresponding inflow and outflow loads for each pollutant respectively. $Q_{\text {max,st }}$ is the maximum outflow for on-line tanks $\left(\mathrm{m}^{3} / \mathrm{d}\right) . h_{\mathrm{o}, \mathrm{st}}$ is the water level in the storage tank $(\mathrm{m})$ when $\mathrm{Q}=Q_{\mathrm{max}, \mathrm{st}} / 2 . h_{\min , \mathrm{st}}$ is the minimum water level in the tank (m). $h_{\mathrm{st}}$ is the water level in the tank $(\mathrm{m}) . C_{\mathrm{st}}$ is a constant for weir overflow. $L_{\text {weir,st }}$ is the length of the weir (m) and $h_{\text {ovf,st }}$ is the height of the overflow weir measured from the bottom of the tank (m). 
Table 2: Summary of modelling details for various storage tank models used in the system-wide BSM.

\begin{tabular}{|c|c|c|c|c|}
\hline & \multicolumn{2}{|c|}{ ON-LINE } & \multicolumn{2}{|c|}{ OFF-LINE } \\
\hline & pass-through & bypass & pass-through & bypass \\
\hline$V_{\text {st }}$ & $\frac{\mathrm{d} V_{\mathrm{st}}}{\mathrm{dt}}=\frac{1}{A_{\mathrm{st}}}\left(Q_{\mathrm{in}, \mathrm{st}}-Q_{\mathrm{out}, \mathrm{st}}-Q_{\mathrm{ovf}, \mathrm{st}}\right)$ & $\frac{\mathrm{d} V_{\mathrm{st}}}{\mathrm{dt}}=\frac{1}{A_{\mathrm{st}}}\left(Q_{\mathrm{in}, \mathrm{st}}-Q_{\mathrm{out}, \mathrm{st}}-Q_{\mathrm{ovf}, \mathrm{st}}\right)$ & $\frac{\mathrm{d} V_{\mathrm{st}}}{\mathrm{dt}}=\frac{1}{A_{\mathrm{st}}}\left(Q_{\mathrm{in}, \mathrm{st}}-Q_{\mathrm{out}, \mathrm{st}}-Q_{\mathrm{ovf}, \mathrm{st}}\right)$ & $\frac{\mathrm{d} V_{\mathrm{st}}}{\mathrm{dt}}=\frac{1}{A_{\mathrm{st}}}\left(Q_{\mathrm{in}, \mathrm{st}}-Q_{\mathrm{out}, \mathrm{st}}-Q_{\mathrm{ovf}, \mathrm{st}}\right)$ \\
\hline$M_{\mathrm{c}, \mathrm{st}}$ & $\frac{\mathrm{d} M_{\mathrm{c}, \mathrm{st}}}{\mathrm{dt}}=X_{\mathrm{c}, \mathrm{in}, \mathrm{st}}-\frac{M_{\mathrm{c}, \mathrm{st}}}{V_{\mathrm{st}}}\left(Q_{\mathrm{out}, \mathrm{st}}+Q_{\mathrm{ovf}, \mathrm{st}}\right)$ & $\frac{\mathrm{d} M_{\mathrm{c}, \mathrm{st}}}{\mathrm{dt}}=X_{\mathrm{c}, \mathrm{in}, \mathrm{st}}-\frac{M_{\mathrm{c}, \mathrm{st}}}{V_{\mathrm{st}}} Q_{\mathrm{out}, \mathrm{st}}-X_{\mathrm{c}, \mathrm{in}} \frac{Q_{\mathrm{ovf}, \mathrm{st}}}{Q_{\mathrm{in}, \mathrm{st}}}$ & $\frac{\mathrm{d} M_{\mathrm{c}, \mathrm{st}}}{\mathrm{dt}}=X_{\mathrm{c}, \mathrm{in}, \mathrm{st}}-\frac{M_{\mathrm{c}, \mathrm{st}}}{V_{\mathrm{st}}}\left(Q_{\mathrm{out}, \mathrm{st}}+Q_{\mathrm{ovf}, \mathrm{st}}\right)$ & $\frac{\mathrm{d} M_{\mathrm{c}, \mathrm{st}}}{\mathrm{dt}}=X_{\mathrm{c}, \mathrm{in}, \mathrm{st}}-\frac{M_{\mathrm{c}, \mathrm{st}}}{V_{\mathrm{st}}} Q_{\mathrm{out}, \mathrm{st}}-X_{\mathrm{c}, \mathrm{in}} \frac{Q_{\mathrm{ovf}, \mathrm{st}}}{Q_{\mathrm{in}, \mathrm{st}}}$ \\
\hline$Q_{\text {out,st }}$ & $\frac{Q_{\mathrm{max}, \mathrm{st}}\left(h_{\mathrm{st}}-h_{\mathrm{min}, \mathrm{st}}\right)^{n_{\mathrm{st}}}}{h_{\mathrm{o}, \mathrm{st}}+\left(h_{\mathrm{st}}-h_{\mathrm{min}, \mathrm{st}}\right)^{n_{\mathrm{st}}}}$ & $\frac{Q_{\mathrm{max}, \mathrm{st}}\left(h_{\mathrm{st}}-h_{\mathrm{min}, \mathrm{st}}\right)^{n_{\mathrm{st}}}}{h_{\mathrm{o}, \mathrm{st}}+\left(h_{\mathrm{st}}-h_{\mathrm{min}, \mathrm{st}}\right)^{n_{\mathrm{st}}}}$ & $Q_{\text {pump,st }}$ & $Q_{\text {pump,st }}$ \\
\hline$X_{\mathrm{c}, \text { out }, \mathrm{st}}$ & $M_{\mathrm{c}, \mathrm{st}} \frac{Q_{\mathrm{out}, \mathrm{st}}}{V_{\mathrm{st}}}$ & $M_{\mathrm{c}, \mathrm{st}} \frac{Q_{\text {out }, \mathrm{st}}}{V_{\mathrm{st}}}$ & $M_{\mathrm{c}, \mathrm{st}} \frac{Q_{\mathrm{out}, \mathrm{st}}}{V_{\mathrm{st}}}$ & $M_{\mathrm{c}, \mathrm{st}} \frac{Q_{\mathrm{out}, \mathrm{st}}}{V_{\mathrm{st}}}$ \\
\hline$Q_{\text {ovf }, \text { st }}$ & $C_{\mathrm{st}} L_{\mathrm{weir}, \mathrm{st}}\left(h_{\mathrm{st}}-h_{\mathrm{ovf}, \mathrm{st}}\right)^{1.5}$ & $C_{\mathrm{st}} L_{\mathrm{weir}, \mathrm{st}}\left(h_{\mathrm{st}}-h_{\mathrm{ovf}, \mathrm{st}}\right)^{1.5}$ & $C_{\mathrm{st}} L_{\mathrm{weir}, \mathrm{st}}\left(h_{\mathrm{st}}-h_{\mathrm{ovf}, \mathrm{st}}\right)^{1.5}$ & $C_{\mathrm{st}} L_{\mathrm{weir}, \mathrm{st}}\left(h_{\mathrm{st}}-h_{\mathrm{ovf}, \mathrm{st}}\right)^{1.5}$ \\
\hline$X_{\mathrm{c}, \mathrm{ovf}, \mathrm{st}}$ & $M_{\mathrm{c}, \mathrm{st}} \frac{Q_{\mathrm{ovf}, \mathrm{st}}}{\mathrm{V}_{\mathrm{st}}}$ & $X_{\mathrm{c}, \mathrm{in}, \mathrm{st}} \frac{Q_{\mathrm{ovf}, \mathrm{st}}}{Q_{\mathrm{in}, \mathrm{st}}}$ & $M_{\mathrm{c}, \mathrm{st}} \frac{Q_{\mathrm{ovf}, \mathrm{st}}}{\mathrm{V}_{\mathrm{st}}}$ & $X_{\mathrm{c}, \mathrm{in}, \mathrm{st}} \frac{Q_{\mathrm{ovf}, \mathrm{st}}}{Q_{\mathrm{in}, \mathrm{st}}}$ \\
\hline
\end{tabular}

*Note that X stands for pollutant load 
Figure 10 presents the behavior of an on-line $\left(\mathrm{ST}_{6}\right)$ (a) and an off-line $\left(\mathrm{ST}_{4}\right)$ (b) storage tank model. In the case of on-line tanks (Figure 10a) simulations show that the outflow $\left(Q_{\text {out,st }}\right)$ varies based on the tank volume $\left(V_{\mathrm{st}}\right)$. Another possibility is restricting the outflow with valves. Figure 10b shows the dynamics of an off-line tank. In this particular case, $V_{\text {st }}$ and $Q_{\text {ovf,st }}$ are determined by $Q_{\text {pump,st. }}$ and $Q_{\mathrm{in}, \mathrm{st} \text {. }}$ The pumps are modelled in such a way that they turn on only during periods when there is no inflow to the off-line storage tank.

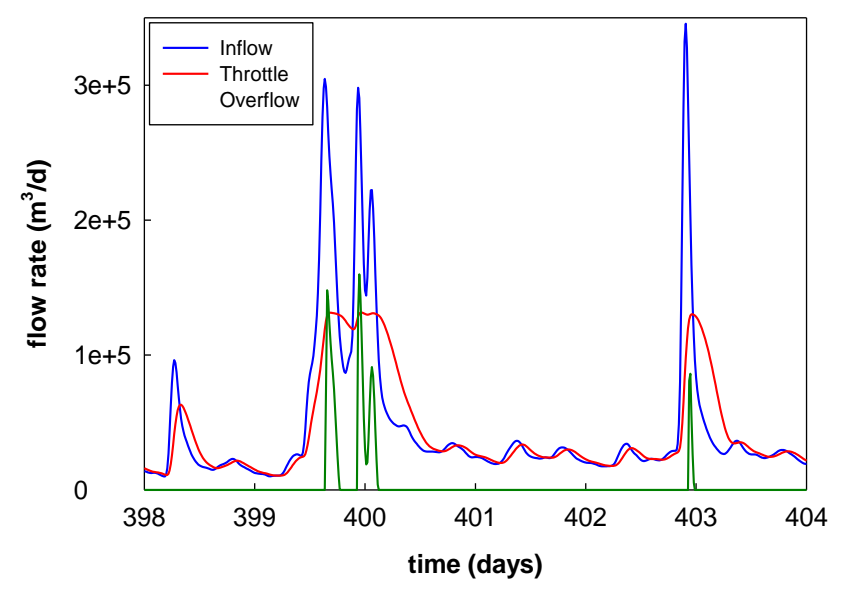

a

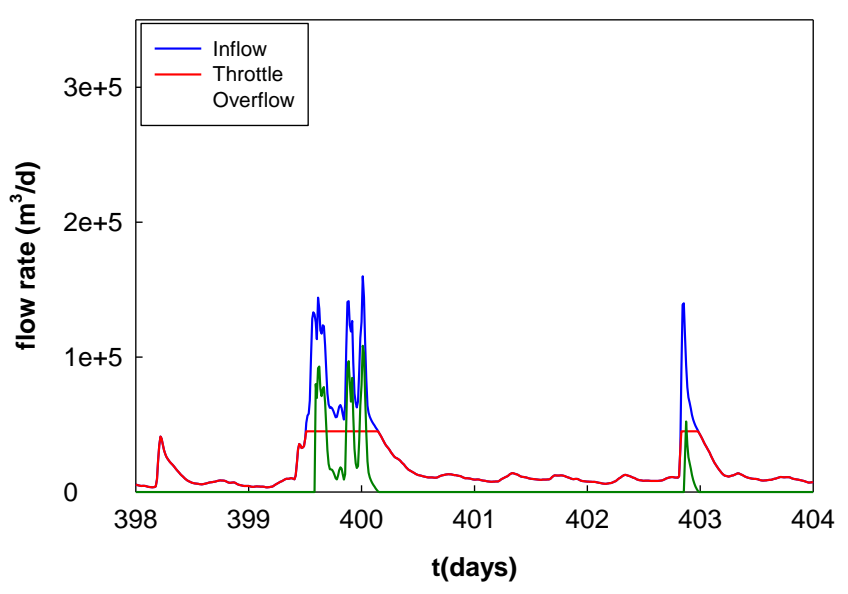

b

Figure 10: Effect of different configurations of the storage tanks on throttle (to the sewer) and overflow: 1) On-line (a); and, 2) Off-line (b).

\section{EVALUATION CRITERIA}

The following evaluation criteria are used for studying the behaviour of the system and the effects of various control strategies/system modifications on its performance. The evaluation considers various overflow locations in the sewer system and also the overflow at the WWTP bypass. Subscript "i" denotes the criteria for a specific overflow location.

1. Yearly overflow frequency $\left(N_{\mathrm{ovf}, \mathrm{i}}\right)$ (events/year): The total number of overflow events per year occurring at a given overflow location. Two overflow events that are separated by less than one hour duration are considered as a single event.

2. Yearly overflow duration $\left(T_{\mathrm{ovf}, \mathrm{i}}\right)$ (days/year): This criterion represents the cumulative sum of overflow duration for all overflow events at one specific location (see Equation 12). Assuming that the simulation is run for $y$ years, for $n$ overflow events each with a time $t(n)$, the yearly overflow duration $\left(T_{\text {ovf }, i}\right)$ is :

$T_{\text {ovf,i }}=\frac{1}{y} \sum_{j=1}^{n} t(j)$

3. Yearly overflow volume $\left(V_{\mathrm{ovf}, \mathrm{i}}\right)\left(\mathrm{m}^{3} /\right.$ year): The total volume of wastewater discharged into receiving waters from a particular overflow location (see Equation 13). Assuming that the simulation is run for $y$ years, for $n$ overflow events each with a duration $t(n)$ (starting at time $t_{\mathrm{o}}(n)$ and ending at time $t_{\mathrm{e}}(n)$ ) and flow rate $Q(t)$, the total overflow volume $\left(\mathrm{m}^{3}\right)\left(V_{\mathrm{ovf}, \mathrm{i}}\right)$ is: 
$V_{\mathrm{ovf}, \mathrm{i}}=\frac{1}{y} \sum_{j=1}^{n} \int_{t_{0}(j)}^{t_{\mathrm{e}}(j)} Q(t) \mathrm{d} t$

4. Yearly overflow pollutant load $\left(X_{\mathrm{ovf}(\mathrm{c}), \mathrm{i}}\right)(\mathrm{kg} / \mathrm{year})$ : This represents the total load in the overflow for a given pollutant $X_{\mathrm{c}}(\mathrm{t})$ at any given overflow location (see Equation 14). Assuming that the simulation is run for $y$ years, for $n$ overflow events each with a duration $t(n)$ (starting at time $t_{o}(n)$ and ending at time $t_{\mathrm{e}}(n)$ ).

$X_{\text {ovf(c),i }}=\frac{1}{y} \sum_{j=1}^{n} \int_{t_{0}(j)}^{t_{\mathrm{e}}(j)} X_{\mathrm{c}}(t) \mathrm{d} t$

5. Overflow quality index $\left(O Q I_{\mathrm{i}}\right)(\mathrm{kg}$ pollution units/day): It is an aggregated pollution index representing the daily total pollution arising from an overflow during a determined period of time $(t)$. $O Q I$ gives an indication of the overall daily pollutant load by assigning weights to individual pollutant loads (see Equation 15). It is defined in a similar fashion as the effluent quality index (EQI) for BSM WWTPs. The influent fractionation proposed by Gernaey et al. (2011) converts the pollution load into ASM state variables in order to further calculate the different types of analytical variables (BOD, COD, TSS, TKN, $\mathrm{NO}_{3}{ }^{-}$and $\mathrm{PO}_{4}{ }^{-3}$ ). The weights for these compounds are $w_{\mathrm{BOD}}, w_{\mathrm{COD}}, w_{\mathrm{TSS}}, w_{\mathrm{TKN}}, w_{\mathrm{NO} 3}$ and $w_{\mathrm{PO} 4}$ respectively. The values for the weights are similar to those used in BSM2. Identical weights are used in order to be able to compare the effect of WWTP effluent discharges and CSOs.

$$
\begin{aligned}
O Q I_{\mathrm{i}}= & \frac{1}{t} \int_{0}^{t}\left[w_{\mathrm{BOD}} X_{\mathrm{Ovf}(\mathrm{BOD}), \mathrm{i}}(t)+w_{\mathrm{COD}} X_{\mathrm{ovf}(\mathrm{COD}), \mathrm{i}}(t)+w_{\mathrm{TSS}} X_{\mathrm{ovf}(\mathrm{TSS}), \mathrm{i}}(t)+\right. \\
& \left.w_{\mathrm{TKN}} X_{\mathrm{Ovf}(\mathrm{TKN}), \mathrm{i}}(t)+w_{\mathrm{NO}_{3}} X_{\mathrm{Ovf}_{\left(\mathrm{NO}_{3}\right), i}}(t)+w_{\mathrm{PO}_{4}} X_{\mathrm{Ovf}_{,}\left(\mathrm{PO}_{4}\right), \mathrm{i}}(t)\right] \mathrm{d} t
\end{aligned}
$$

6. Yearly exceedance duration $\left(T_{\operatorname{exc}(c), i}\right)$ : It is the total duration per year for which a certain pollutant concentration exceeds a specified concentration threshold $\left(C_{\mathrm{th}}\right)$. Therefore, for a particular overflow event $n$, with concentration of a particular pollutant $C(t)$, the exceedance duration for the event $n$ and the pollutant $c$ $\left(t_{\text {exe }}(\mathrm{c}, \mathrm{n})\right)$ and for all the events occurring in $y$ years at an overflow location, $\left(T_{\operatorname{exc}(\mathrm{c}), \mathrm{i}}\right)$ is defined as stated in Equations 16 and 17. The threshold concentrations (at various overflow locations) for TSS, TKN and $\mathrm{PO}_{4}$ used in this study are $30 \mathrm{~g} / \mathrm{m}^{3}, 5 \mathrm{~g} / \mathrm{m}^{3}$ and $0.5 \mathrm{~g} / \mathrm{m}^{3}$, respectively. It should be noted that these values are similar to the effluent discharge limits for BSM WWTPs. $\mathrm{PO}_{4}$ is included although it is not toxic. It is due to the fact that the excess $\mathrm{PO}_{4}$ can lead to eutrophication (especially in rivers with phosphorus limitation) and therefore depletion in oxygen concentration.

$$
\begin{aligned}
& t_{\mathrm{exc}, \mathrm{i}}(c, n)=\sum\{(t+1)-t\} \quad \text { when } C(t)>C_{\mathrm{th}} \\
& T_{\mathrm{exc}(\mathrm{c}), \mathrm{i}}=\frac{1}{y} \sum_{j=1}^{n} t_{\mathrm{exc}, \mathrm{i}}(c, j)
\end{aligned}
$$

7. Hourly maximum concentration $\left(C_{\max (\mathrm{c}), \mathrm{i}}\right)$ : Maximum exceedance values for a certain concentration are defined for a specific time interval. In this study, 1-hour maximum exceedance is used. It is the highest 
concentration that is continuously discharged for a period of at least 1 hour. Similarly, maximum concentrations for 2-hour, 6-hour time periods etc. can be defined.

The above criteria can be classified in two different ways based on: 1) location; and, 2) impact. In terms of location, the criteria can be defined on a: 1) local level (for each overflow location i); and, 2) global level (taking into account all the overflows and the bypass at the WWTP). From an impact perspective, the criteria are divided into those describing: 1$)$ cumulative effects ( $N_{\text {ovf }}, T_{\text {ovf }}, V_{\text {ovf }}, X_{\text {ovf }}$ and $\left.O Q I\right)$; and, 2) acute effects ( $T_{\operatorname{exc}(\mathrm{c})}$ and $\left.C_{\max (\mathrm{c})}\right)$ on the receiving waters. These criteria are only an indirect representation of the effect of overflow discharges on receiving waters. They draw inspiration from similar criteria used in assessment of river water quality (Schutze et al., 2002; FWR, 1998). To consider pollutant quality in the sewer system evaluation, we used these additional criteria even though they are not commonly encountered in CSO evaluation literature. In this paper, the evaluation criteria $T_{\operatorname{exc}(c)}$ and $C_{\max (c)}$ are applied only to TKN in order to limit the number of evaluation criteria.

\section{CASE STUDIES}

This section presents simulation results from implementing different scenarios using the catchment and sewer network model (see Table 3). The evaluated control alternatives employ storage tanks as control handles. The control actuators are generally valves/gates/pumps that regulate the outflow from these storage tanks. Examples of the evaluation of both local and global (sewer \& catchment system) control strategies are presented here. The strategies are:

- $\quad$ Reducing the bypass at the WWTP (C1);

- Reducing the total overflows from the system (C2).

Apart from evaluation of control strategies, the presented model can also be used to study the influence of structural modifications of the sewer network/catchment. To demonstrate this, two possibilities are implemented and their effects are analyzed:

- Modification of $\mathrm{SC}_{5}$ from a separate sewer system to a combined sewer system (S1);

- Inclusion of an additional storage tank at the WWTP influent (S2).

The following section describes the effects of each of these evaluated alternatives from a global and local perspective with the set of criteria defined in Section 5.

Table 3. Summary of the global evaluation criteria for the different scenarios. No control (NC); C1 and C2 are the control strategies. S1 and S2 are the scenarios with structural modifications.

\begin{tabular}{llllll}
\hline Criteria & NC & C1 & C2 & S1 & S2 \\
\hline Cumulative effects & 137 & 142 & 141 & 82 & 137 \\
$N_{\text {ovf }}$ (events/year) & 71 & 71 & 71 & 21 & 71 \\
$T_{\text {ovf }}$ (days/year) & 830,192 & 654,724 & 642,846 & 722,650 & 678,055 \\
$V_{\text {ovf }}$ (m³/year) & 3,110 & 2,118 & 2,068 & 2,937 & 2,076 \\
OQI (kg pollutant units/day) & & & & & \\
Acute effects & & & & \\
\hline
\end{tabular}




\begin{tabular}{llllll}
\hline$T_{\text {exc }(\mathrm{TKN})}($ days/year $)$ & 49.0 & 50.7 & 50.6 & 20.3 & 47.6 \\
$C_{\max (\mathrm{TKN})}\left(\mathrm{g} / \mathrm{m}^{3}\right)$ & 51.1 & 51.1 & 51.1 & 48.8 & 51.1 \\
\hline
\end{tabular}

\subsection{Reducing the bypass at the WWTP (C1)}

The existing configuration of the BSM2 layout includes a bypass at the inlet of the WWTP which redirects any excess inflow reaching the plant (inflow $>60,000 \mathrm{~m}^{3} / \mathrm{d}$ ) to the effluent section where it is mixed with the treated wastewater (Gernaey et al., 2014). Storage tank $6\left(\mathrm{ST}_{6}\right)$ is located upstream of the WWTP. A rule based strategy (control algorithm) is developed to better utilize the available storage volume in $\mathrm{ST}_{6}$. The sensor inputs (measured variable) to the control strategy are: 1) flow rate at $\mathrm{ST}_{6}$ influent; and, 2) level measurement from $\mathrm{ST}_{6}$ (max. level is $5 \mathrm{~m}$ ). When the inflow to $\mathrm{ST}_{6}$ exceeds $60,000 \mathrm{~m}^{3} / \mathrm{d}$ and there is storage capacity available (level $<4 \mathrm{~m}$ ), the outflow from the tank is restricted using a valve (control variable). The valve opening is reduced to $65 \%$ under these conditions. In other situations, the valve is fully open. The reduced valve opening will lead to more storage and hence a better utilization of the tank capacity. As the tank is reaching its maximum capacity ( $\mathrm{h}>4 \mathrm{~m}$ ), the valve is fully opened so that the control will not lead to excess overflow at $\mathrm{ST}_{6}$ while trying to reduce the bypass at the WWTP.

Table 4. Summary of the local evaluation criteria at $\mathrm{ST}_{6}$ and bypass for the scenario $\mathrm{C} 1$.

\begin{tabular}{llllc}
\hline Criteria & \multicolumn{3}{c}{$\mathbf{S T}_{6}$} & \multicolumn{2}{c}{ Bypass } \\
\cline { 2 - 5 } & NC & C1 & NC & C1 \\
\hline Cumulative effects & 5 & 8 & 79 & 75 \\
$N_{\text {ovf }}($ events/year) & 0.6 & 0.9 & 18 & 21 \\
$T_{\text {ovf }}$ (days/year) & 21,379 & 32,870 & 473,341 & 286,381 \\
$V_{\text {ovf }}\left(\mathrm{m}^{3} /\right.$ year) & 32 & 67 & 2,072 & 1,045 \\
$O Q I$ (kg pollutant units/day) & & & & \\
Acute effects & 0.3 & 0.7 & 17.2 & 18.8 \\
$T_{\text {exc(TKN) }}($ days/year) & 8.2 & 12.2 & 47.8 & 47.5 \\
$C_{\max (\text { TKN) }}\left(\mathrm{g} / \mathrm{m}^{3}\right)$ & & & & \\
\hline
\end{tabular}

Table 4 compares the evaluation criteria at $\mathrm{ST}_{6}$ (overflow) and bypass (BP). Results show that the yearly overflow frequency $\left(N_{\text {ovf, } \mathrm{sC} 6}\right)$ at $\mathrm{ST}_{6}$ increased while it reduced at the bypass $\left(N_{\text {ovf, bp }}\right)$. Yearly overflow duration shows an increase at both the locations $\left(T_{\text {ovf,SC6, }}, T_{\text {ovf,bp }}\right)$. The major outcome from the control is an improvement in both yearly overflow volume $\left(V_{\mathrm{ovf}, \mathrm{bp}}\right)(39 \%)$ and overflow quality index $\left(O Q I_{\mathrm{bp}}\right)(50 \%)$ at the bypass. The improvements at the bypass led to a drop in performance at $\mathrm{ST}_{6}$. Thus, yearly overflow volume increased by $54 \%\left(V_{\mathrm{ovf}, \mathrm{SC} 6}\right)$ and the overflow quality index $\left(O Q I_{\mathrm{SC} 6}\right)$ increased significantly by $110 \%$ at $\mathrm{ST}_{6}$. The above criteria describing the cumulative effects indicate an improvement at the bypass at the cost of decreased performance at $\mathrm{ST}_{6}$. Additionally, the effect of the control strategy is also analyzed using criteria that describe acute effects. Yearly exceedance duration for TKN ( $\left.T_{\operatorname{exc}(\mathrm{TKN}), \mathrm{bp}}, T_{\operatorname{exc}(\mathrm{TKN}), \mathrm{ST} 6}\right)$ at both locations increased due to the control strategy. Hourly maximum concentration for TKN remains almost similar at the bypass $\left(C_{\max (\mathrm{TKN}), \mathrm{bp}}\right)$ while increasing at $\mathrm{ST}_{6}\left(C_{\max (\mathrm{TKN}), \mathrm{ST} 6}\right)$. From a global point of view, Table 3 reveals that $\mathrm{C} 1$ has led to a decrease in the yearly overflow volume $\left(V_{\mathrm{ovf}}\right)$ discharged into the receiving water by $21 \%$. Also, the overflow quality index (OQI) was reduced by $32 \%$. The control strategy did not have any major 
impact on the acute effects $\left(T_{\operatorname{exc}(\mathrm{TKN})}, C_{\max (\mathrm{TKN})}\right)$. Summarizing, it can be said that $\mathrm{C} 1$ successfully decreased the cumulative pollutant load to the receiving water but was not effective in handling critical situations.

\subsection{Reducing the total overflows from the system (C2)}

In order to utilize the available storage capacity in a better way, several local control strategies similar to the one employed in Section 6.1 (C1) are implemented at all storage locations with overflow structures (see Figure 1). For $\mathrm{ST}_{2}, \mathrm{ST}_{3}$ and $\mathrm{ST}_{6}$, the measured variables are water levels from the respective tanks. If the level is less than $4 \mathrm{~m}$ ( $\max$ level $=5 \mathrm{~m}$ ), the valve opening is reduced to $65 \%$. It is otherwise fully opened (control algorithm). For $\mathrm{ST}_{4}$, which is an off-line tank, the throttle flow to the main sewer (wastewater with flow rate in excess of this is directed to $\mathrm{ST}_{4}$ ) is controlled based on the water level measurement (control variable). If the level in $\mathrm{ST}_{4}$ is less than $4 \mathrm{~m}$, the throttle flow is $40,000 \mathrm{~m}^{3} / \mathrm{d}$, which means that any flow in excess of $40,000 \mathrm{~m}^{3} / \mathrm{d}$ reaches the storage tank. When the tank is filled above a level of $4 \mathrm{~m}$, the throttle flow is increased to $55,000 \mathrm{~m}^{3} / \mathrm{d}$ to allow passing more wastewater through the main sewer. Hence, the algorithm tries to send more water downstream than in the no control case $\left(45,000 \mathrm{~m}^{3} / \mathrm{d}\right)$. This is an example of various non-interacting local control strategies developed with an overall aim to reduce the cumulative overflow volume/load.

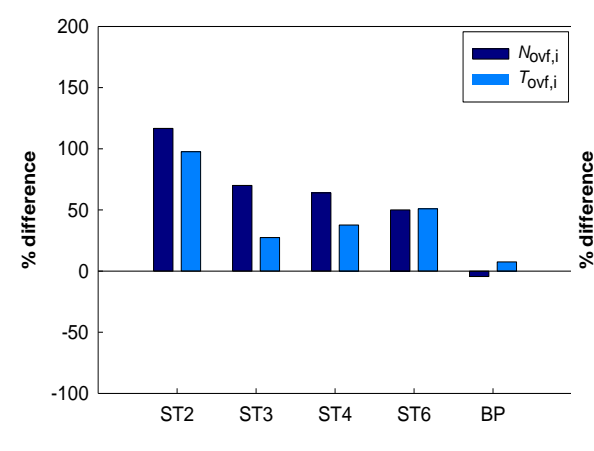

a

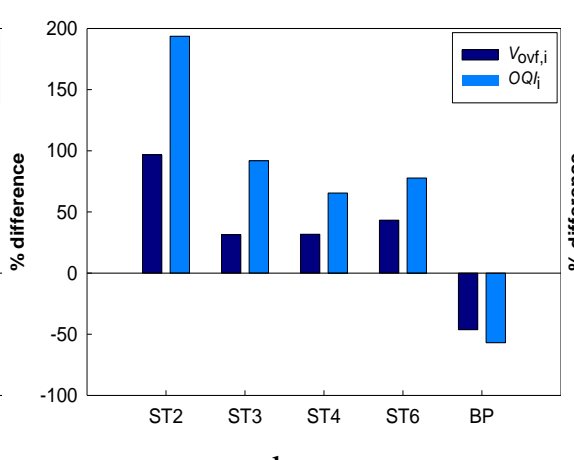

b

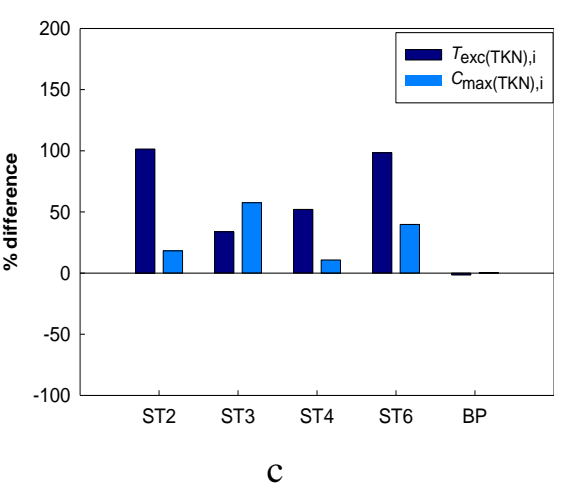

$\mathrm{C}$

Figure 11: Evaluation of various performance criteria comparing the default case (NC) with the global control strategy (C2). The percentage difference in performance between NC and C2 is shown, evaluated for the criteria: a) $N_{\text {ovf,i }}$ and $T_{\text {ovf,i }}$; b) $V_{\text {ovf,i }}$ and $O Q I_{\mathrm{i}}$; and, c) $T_{\text {exc(TKN),i }}$ and $C_{\max (\mathrm{TKN}), \mathrm{i}}$ in various storage tanks (ST2, ST3, ST4, ST6) and the bypass (BP).

The implementation of $\mathrm{C} 2$ has led to mixed results (Figure 11) at local level. The performance at $\mathrm{ST}_{2}, \mathrm{ST}_{3}$, $\mathrm{ST}_{4}$ and $\mathrm{ST}_{6}$ dropped for all evaluation criteria. The only location that showed improvement is the bypass (BP). At the bypass, criteria that showed major improvements are yearly overflow volume $(46 \%)\left(V_{\text {ovf,bp }}\right)$ and the $O Q I_{\mathrm{bp}}(57 \%)$. The acute effects at the bypass did not change much due to the control. Looking at the entire system (see Table 3), with an improved utilization of the available storage $(\mathrm{C} 2)$, a drop in the yearly overflow volume (23\%) $\left(V_{\text {ovf }}\right)$ and overflow quality index $(34 \%)(O Q I)$ is observed while there is no major change in the acute effects $\left(C_{\mathrm{max} ; \mathrm{TKN}}, T_{\mathrm{exc}, \mathrm{TKN}}\right)$. Although, the control led to lower overall quality in comparison to the default situation at many overflow locations, it had a net positive effect on the entire system. The results obtained from the global control strategy are very similar to those obtained from the 
control strategy described in $6.1(\mathrm{C} 1)$. This is due to the fact that overflow at $\mathrm{ST}_{6}$ and the bypass are the major contributors to the total overflow from the system. In fact, it can be said that the improvement observed at the bypass lead to an overall improvement of the system performance even though the other overflow locations underperformed in comparison to the default case. Also, it should be noted that there are a large number of variables that are chosen by trial and error for this control strategy (e.g. valve opening for $\mathrm{ST}_{2}, \mathrm{ST}_{3}, \mathrm{ST}_{4}$ and $\mathrm{ST}_{6}$, throttle flow for $\mathrm{ST}_{4}$ etc.). A more sophisticated optimization procedure can potentially lead to better results.

\subsection{Modification of $\mathrm{SC}_{5}$ from a separate sewer system to a combined sewer system (S1)}

During the evaluation of $\mathrm{C} 1$ and $\mathrm{C} 2$, it was noticed that due to the existence of a separate sewer system at $\mathrm{SC}_{5}$, any stormwater in $\mathrm{SC}_{5}$ eventually reaches the river. This means that all rain events lead to an overflow at $\mathrm{ST}_{5}$ as they cannot be redirected to the WWTP as in the case of a combined sewer system. A possible modification to the system is to convert $\mathrm{SC}_{5}$ to a combined sewer system which will lead to reduction in the overflow volume/load from $\mathrm{SC}_{5}$ and hence potentially improve the overall system behavior. It is assumed that the volume of the storage tank remains unchanged.

Table 5. Summary of the local evaluation criteria at $\mathrm{ST}_{5}$ for scenario $\mathrm{S} 1$.

\begin{tabular}{lll}
\hline Criteria & NC & S1 \\
\hline Cumulative effects & 134 & 2 \\
$N_{\text {ovf }}($ events/year) & 71 & 0 \\
$T_{\text {ovf }}$ (days/year) & 268,821 & 2,132 \\
$V_{\text {ovf }}\left(\mathrm{m}^{3} /\right.$ year) & 864 & 2 \\
$O Q I$ (kg pollutant units/day) & & \\
Acute effects & 40.7 & 0.0 \\
$T_{\text {exc(TKN) }}($ days/year) & 51.1 & 2.9 \\
$C_{\max (T K N)}\left(\mathrm{g} / \mathrm{m}^{3}\right)$ & & \\
\hline
\end{tabular}

Table 5 shows that at $\mathrm{ST}_{5}$, the improvements are very clearly visible. The change, as expected, led to orders of magnitude difference in all the evaluation criteria at the local level. Given that there are only two overflow events after the system modification is done, the overflow quality index $\left(O Q I_{\mathrm{ST} 5}\right)$ has also dropped significantly from $864 \mathrm{~kg}$ pollutant units/day to only $2 \mathrm{~kg}$ pollutant units/day. Also, as can be noticed, the acute effects improved significantly. The yearly exceedance duration $\left(T_{\mathrm{exc}(\mathrm{TKN}), \mathrm{STS})}\right)$ and hourly maximum concentration $\left(C_{\max (\mathrm{TKN}) \mathrm{ST} 5}\right)$ declined considerably (100\% and $94 \%$ respectively). The results when looked at from a system-wide perspective show the influence of $\mathrm{ST}_{5}$ on the overall performance (see Table 3). As expected, it led to a significant drop in the yearly overflow frequency $\left(N_{\mathrm{ovf}}\right)(41 \%)$ and yearly overflow duration $\left(T_{\mathrm{ovf}}\right)(71 \%)$. This is expected as the separate sewer system (that discharges into the river for all rain events) is now modified into a combined sewerage where the discharges happen only if the storage capacity in ST5 is exceeded ( 2 events/year in this case). Although, there is a drop in yearly overflow volume ( $\left.V_{\text {ovf }}\right)$ (13\%), the discharges at ST5 and downstream are now more polluted due to mixing with the domestic wastewater from SC5. A significant drop in $O Q I$ is observed at ST5, but this does not lead to overall improvement in $O Q I$. This is due to the fact that the discharges are now happening elsewhere (at ST6 and the 
bypass). Hence, the overflow quality index (OQI) has only improved by $6 \%$. The changes also caused major improvements to the acute criteria. Yearly exceedance duration and hourly maximum concentration for TKN $\left(T_{\operatorname{exc}(\mathrm{TKN})}, C_{\max (\mathrm{TKN})}\right)$ improved by $59 \%$ and $5 \%$ respectively. Hence, the system modification can be analyzed at various levels. In terms of its impact on the local overflow performance, the improvement is phenomenal. From an overall point of view, the changes did lead to major improvements but the improvements at $\mathrm{SC}_{5}$ due to the change are masked by the overall system performance. Also it should be noted that such a change can be detrimental to the WWTP performance, especially if the WWTP is operating at its maximum capacity or the area is prone to heavy rainfall events.

\subsection{Inclusion of an additional storage tank at the WWTP influent (S2)}

The last evaluated scenario studies the impact of including an additional storage tank at the BSM2 WWTP influent. Hence, the system configuration is modified by including an on-line pass-through tank with pump at the WWTP inlet. The volume of the storage tank is $8,000 \mathrm{~m}^{3}$. The additional storage tank is aimed at reducing the bypass at the WWTP.

Again, the storage tank has resulted in considerable improvements in all the evaluation criteria at the local level (see Table 6). At the bypass location, the effect of additional storage is clearly visible on the criteria for cumulative effects. Drops in yearly overflow frequency (56\%) and yearly overflow duration (46\%) are observed $\left(N_{\text {ovf,bp }}, T_{\text {ovf;bp }}\right)$. The yearly overflow volume $\left(V_{\text {ovf;bp }}\right)$ and the overflow quality index $\left(O Q I_{\mathrm{bp}}\right)$ are reduced by $32 \%$ and $50 \%$, respectively. The storage tank addition was also successful in decreasing the acute effects described by yearly exceedance duration and hourly maximum concentration for TKN ( $T_{\mathrm{exc}(\mathrm{TKN}), \mathrm{bp}}$, $C_{\max (\mathrm{TKN}) \text {,bp })}$ as the tank helps in equalizing the incoming pollutant load and hence reduces the high concentration peaks. While comparing the changes in the performance of the entire system (see Table 3), the storage tank has not made any major changes to the yearly overflow frequency $\left(N_{\text {ovf }}\right)$ and yearly overflow duration $\left(T_{\mathrm{ovf}}\right)$ as it is not the location with the highest duration and frequency in the default case. An $18 \%$ drop in the overall yearly overflow volume $\left(V_{\text {ovf }}\right)$ and a $33 \%$ decrease in system-wide overflow quality index (OQI) are noticed. The modification also marginally decreases the yearly exceedance duration for TKN $\left(T_{\text {exc(TKN) }}\right)$ by $3 \%$ indicating that the bypass location was one of the main contributors to the high concentration loads. In terms of hourly maximum concentration $\left(C_{\max (\mathrm{TKN})}\right)$, no changes are observed as the maximum concentration events are not occurring at the bypass. Finally, it can be said that the storage tank was useful in equalizing the incoming pollutants and acts as a buffer to store additional wastewater during rain events. In spite of the high costs involved in addition of a storage tank at the WWTP influent, the overall performance improvement from such a system modification is similar to that from the control modifications. This is due to the fact that the effect of $\mathrm{C} 1, \mathrm{C} 2$ and $\mathrm{S} 2$ is similar. They all lead to reduced overflows from the bypass. While the control strategies achieve this by modifying the operation of upstream storage tanks, the structural modification S2 does this by including additional storage. Also, C1, C2 and S2 were not successful in reducing the overall overflow frequency and duration $\left(N_{\text {ovf }}, T_{\text {ovf }}\right)$. As SC5 is the major reason for high $N_{\text {ovf }}$ 
and $T_{\text {ovf }}$ (as this is a separate sewer system and all rain events will lead to an overflow), only $\mathrm{S} 1$ is successful in reducing $N_{\text {ovf }}$ and $T_{\text {ovf }}$ whereas other strategies could reduce $V_{\text {ovf }}$ and $O Q I$ as they try to reduce the total overflow volumes.

Table 6. Summary of the local evaluation criteria at the bypass for scenario S2.

\begin{tabular}{lll}
\hline Criteria & NC & S2 \\
\hline Cumulative effects & 79 & 35 \\
$N_{\text {ovf }}$ (events/year) & 18 & 10 \\
$T_{\text {ovf }}$ (days/year) & 473,341 & 321,204 \\
$V_{\text {ovf }}\left(\mathrm{m}^{3} /\right.$ year) & 2,072 & 1,037 \\
$O Q I(\mathrm{~kg}$ pollutant units/day) & & \\
Acute effects & 17.2 & 8.2 \\
$T_{\text {exc(TKN) }}($ days/year) & 47.8 & 31.7 \\
$C_{\max (\mathrm{TKN})}\left(\mathrm{g} / \mathrm{m}^{3}\right)$ & & \\
\hline
\end{tabular}

\section{DISCUSSION}

The catchment and sewer extension to the BSM WWTP model has been described in detail in this paper. The model has successfully described the dynamics of wastewater generation from various sources (domestic, industrial) during dry weather and rain periods. Additionally, infiltration to the sewers is also included. A sewer network model that can simulate the transport of the generated wastewater has been implemented. The model can also describe the first flush of the particulate (sewer) pollutants during rain events. Models for different storage tank configurations together with control actuators, such as valves and pumps, are described. Overflow based evaluation criteria have been defined and are used to evaluate the performance of control strategies and structural modifications. Finally, the suitability of the catchment and sewer extension to describe the dynamics of wastewater generation and transport as well as objective evaluation of control strategies has been successfully demonstrated. These case studies are only illustrative and do not represent any possible strategies that can be replicated in real catchments. The focus has been on demonstrating the capabilities of the model.

In general, benchmarking tools are developed for the evaluation of control strategies for a defined system layout. In the case of WWTP benchmark models, these models are employed not only for control strategy evaluation but are also extensively used for other purposes like model development, diagnosis, monitoring etc. (Gernaey et al., 2014). In a similar fashion, the spatial extension of the benchmark system can also be employed to develop and evaluate control strategies and structural modifications as illustrated by the case studies. Additional scenarios like adapting the benchmarking tool to a particular catchment and evaluating scenarios specific to any individual urban catchment are also possible.

\subsection{Benchmark system layout}

The system layout presented here is an upscaled version of the ATV case study and very similar to the layout used in the studies carried out in Schutze et al. (2002). Through various discussions at different stages of the development of this model, it has been clear that the sewer system layouts vary considerably across different 
urban catchments and in different countries. It is unlikely that any proposed sewer layout will closely resemble a majority of the sewer system layouts. Hence, the focus in this work has therefore been on choosing a reasonable system layout, with the purpose of providing a framework for the evaluation of control strategies. Although, the variation in layout will influence the performance of control strategies, the control schemes identified using the benchmark model can potentially be transferred to other layouts. Nevertheless, we plan to work in different directions to address this issue in the future: 1) Presenting more than one benchmark layout; and, 2) Comparing the performance of control strategies on the benchmark layout with that on actual catchment layouts. This will provide us with additional insight on the extent to which knowledge derived from the extended BSM layout can be used to address issues in other urban catchments.

\subsection{Adaptation to other catchments}

As in the case of BSM1 and BSM2, many users might be interested in adapting the extensions to their catchment layouts. It is for this purpose that the model building is performed in a block-wise manner making it easy for future users to adapt model blocks for any specific system layout. The first step in the process will be modifying the catchment layout. The major sections that will need modification (apart from modifying the layout) are influent dynamics, sewer reservoirs and storage tank characteristics. A list of key parameters required to be adapted are available in Appendix 1. Although users have the choice of using commercial softwares for this purpose, the main advantages of these extensions are that it is a complete toolbox (comprising of a system layout, underlying models and evaluation criteria) that is: 1) flexible for adaptations; 2) freely distributed; and, 3) open source (which means users can look into the code and even modify it, if required).

\subsection{Model limitations}

However, owing to the conceptual approach used for modelling the sewer network and other hydraulic elements, the model has some limitations. It is not suitable to evaluate scenarios where phenomena like pressurized flow, backwater effects and surface flooding are prominent. Also, biological reactions within the sewer system are not yet considered (Huisman, 2001). The transport and accumulation of particulate pollutants is dealt with in a simplified way. Additionally, the rainfall generator model is also limited in its ability to reproduce extreme rain events. Hence, the rainfall generator is more suitable for evaluating control applications rather than performing studies that are more specific to high intensity rainfall.

\subsection{Future directions}

The current paper mainly deals with sewer overflows.. It is well established that any integrated evaluation of the urban wastewater systems should be focused on improving the receiving water quality. Although the current evaluation criteria give an indirect indication on the impact of sewer overflows on river water quality, a direct river quality based evaluation will be a more preferable approach. For such an analysis, the benchmark system extension discussed here should be combined with a river water quality model (RWQM1) (Reichert et al., 2001) and also be integrated with the BSM family of WWTP models. River quality based 
evaluation criteria should be developed. This paper is the first attempt at developing spatial extensions to the BSM platform, and more work is in progress in the direction of integrating the model with a WWTP and river system.

With respect to the control strategies and system modifications presented as case studies, it is essential to highlight the fact that the results also depend to a great extent on parameters like valve opening for on-line tanks, throttle flow for off-line tanks and the level and flow rate values that act as inputs to these rule-based control strategies. Mathematical optimization procedures can play a major rule in identifying the most suitable set points in such cases (Fu et al., 2008). Other options that are not evaluated in this case study are changes to the catchment characteristics. For example: 1) restricting industries not to have peak loads on Fridays; and, 2) addition of a seventh sub-catchment to the system etc. The effect of such changes on wastewater generation and its subsequent impact on sewer dynamics can be analyzed.

Last but not least is the interfacing between water quality models for different sub systems. Since, the catchment and the sewer models use the same variables, there is no need for interfacing between them. The interface between sewer and WWTP is performed using the elemental balancing approach proposed by Volcke et al. (2006) and Grau et al. (2007). As the elemental composition based approach was originally proposed in the RWQM1, future interfaces between sewer/river and WWTP/river will also use the same approach.

\section{CONCLUSIONS}

The presented model will enable practitioners/researchers to evaluate integrated control strategies/structural modifications (within catchment and sewer system) using overflow based evaluation criteria. The key findings of the presented study can be summarized in the following points:

1) The catchment model is capable of generating (dry/ wet weather) flow rate and pollution loads (soluble/particulate) through the combination of four different sub-models (DOM, IND, INF, SW). These sub-models contribute to the total wastewater profile with different types of dynamics.

2) The sewer model can mimic wastewater transport and storage using three different sub-models (TRANSPORT, FIRST FLUSH and STORAGE). These models account for sewer length, a sudden increase of particulates at the start of a rain event and wastewater storage to avoid combined sewer overflows.

3) A set of evaluation criteria are proposed to assess the (cumulative/acute) effects of different control strategies on both local and global level for different overflow locations. The cumulative effects are evaluated in terms of overflow frequency, duration, volume and loads. The acute effects are indicated using the criteria of exceedance duration and hourly maximum concentration for TKN. 
4) Case studies highlighting the potential applications of the framework by implementing control strategies (local and global) and structural modifications (in both the catchment and sewer network) are presented. Varying levels of performance improvement are observed in these scenarios.

The model is an important contribution to the wastewater engineering field, especially in the direction of developing systematic procedures to evaluate "outside the fence" control strategies and potentially to be combined with existing and successful wastewater treatment plant evaluation models. Work is in progress to extend this model further to include a river system as well. This will in the future result in a complete system-wide UWS benchmark simulation model for analysis of integrated control strategies.

\section{ACKNOWLEDGEMENTS}

Dr. Flores-Alsina and Mr. Saagi gratefully acknowledge the financial support provided by the People Program (Marie Curie Actions) of the European Union's Seventh Framework Programme FP7/2007-2013 under REA agreement 329349 (PROTEUS) and 289193 (SANITAS) respectively. The authors gratefully acknowledge the feedback provided by Professor Peter A. Vanrolleghem, Canada Research Chair in Water Quality Modelling, Université Laval, Quebec, Canada during the development of the model. 


\section{REFERENCES}

Astaraie-Imani, M., Kapelan, Z., Fu, G. and Butler, D. (2012). Assessing the combined effects of urbanisation and climate change on the river water quality in an integrated urban wastewater system in the UK. J. Env. Mgmt, 112, $1-9$.

ATV (1992). A 128 - Richtlinien für die Bemessung und Gestaltung von Regenentlastungsanlagen in Mischwasserkanälen. Deutsche Vereinigung für Wasserwirtschaft, Abwasser und Abfall e.V. (in German).

Bach, P.M., Rauch, W., Mikkelsen, P.S., McCarthy, D.T. and Deletic, A. (2014). A critical review of integrated urban water modelling - urban drainage and beyond. Env. Mod. Soft., 54, 88-107.

Benedetti, L., Bixio, D., Claeys, F. and Vanrolleghem, P.A. (2008). Tools to support a model-based methodology for emission/immission and benefit/cost/risk analysis of wastewater systems that considers uncertainty. Env. Mod. Soft., 23(8), 1082-1091.

Benedetti, L., De Keyser, W., Nopens, I. and Vanrolleghem, P.A. (2010). Probabilistic modelling and evaluation of wastewater treatment plant upgrades in a water quality based evaluation context. J. Hydr-inf., 12(4), 380-398.

Benedetti, L., Langeveld, J.G., Comeau, A., Corominas, L., Daigger, G.T., Martin, C., Mikkelsen, P.S., Vezzaro, L., Weijers, S. and Vanrolleghem, P.A. (2013). Modelling and monitoring of integrated urban wastewater systems: Review on status and perspectives. Wat. Sci. Tech., 68(6), 1203-1215.

Benedetti, L., Meirlaen, J. and Vanrolleghem, P.A. (2004). Model connectors for integrated simulations of urban wastewater systems. Sewer networks and processes within urban water systems, IWA Publishing, London, UK, 1321.

Borsányi, P., Benedetti, L., Dirckx, G., De Keyser, W., Muschalla, D., Solvi, A.-M., Vandenberghe, V., Weyand, M. and Vanrolleghem, P.A. (2008). Modelling real time control options on benchmark sewer systems. J. Env. Eng. Sci., 7, 395-410.

Buishand, T.A. (1978). Some remarks on the use of daily rainfall models. J. Hyd., 36(3), 295-308.

Butler, D. and Davies, J. (2011). Urban drainage. 3rd Edition, Taylor \& Francis, London, UK.

Erbe, V. and Schütze, M. (2005). An integrated modelling concept for immission-based management of sewer system, wastewater treatment plant and river. Wat. Sci. Tech., 52(5), 95-103.

Flores-Alsina, X., Saagi, R., Lindblom, E., Thirsing, C., Thornberg, D., Gernaey, K.V. and Jeppsson, U. (2014). Calibration and validation of a phenomenological influent pollutant disturbance scenario generator using full-scale data. Wat. Res., 51, 172-185.

Freni, G., Mannina, G. and Viviani, G. (2011). Role of Modeling Uncertainty in the Estimation of Climate and Socioeconomic Impact on River Water Quality, J. Wat. Res. Plan. Mgmt., 138(5), 479-490.

Fu, G. and Butler, D. (2012). Frequency analysis of river water quality using integrated urban wastewater models. Wat. Sci. Tech., 65(12), 2112-2117.

Fu, G., Butler, D. and Khu, S.T. (2008). Multiple objective optimal control of integrated urban wastewater systems. Env. Mod. Soft., 23(2), 225-234.

Fu, G., Butler, D. and Khu, S.T. (2009b). The impact of new developments on river water quality from an integrated system modelling perspective. Sci. Tot. Env., 407(4), 1257-1267.

Fu, G., Khu, S.-T. and Butler, D. (2009a). Use of surrogate modelling for multiobjective optimisation of urban wastewater systems. Wat. Sci. Tech., 60(6), 1641-1647.

FWR. (1998). Manual, Urban Pollution Management, 2nd edition, Foundation for Water Research, Marlow, UK. 
Gernaey, K.V., Flores-Alsina, X., Rosen, C., Benedetti, L. and Jeppsson, U. (2011). Phenomenological modelling approach to generate WWTP disturbance scenarios. Env. Mod. Soft., 26, 1255-1267.

Gernaey, K.V., Jeppsson, U., Vanrolleghem, P.A. and Copp, J.B. (2014). Benchmarking of Control Strategies for Wastewater Treatment Plants. IWA Publishing Scientific and Technical Report Series, Technical Report no. 23, London, UK.

Grau, P., de Gracia, M., Vanrolleghem, P.A. and Ayesa, E. (2007). A new plant-wide modelling methodology for WWTPs. Wat. Res., 41(19), 4357-4372.

Guo, L., Porro, J., Sharma, K.R., Amerlinck, Y., Benedetti, L., Nopens, I. and Vanrolleghem, P.A. (2012). Towards a benchmarking tool for minimizing wastewater utility greenhouse gas footprints. Wat. Sci. Tech., 66(11), 24832495 .

Hager, W.H. (2010). Wastewater Hydraulics. Springer Berlin, Heidelberg, Germany.

Harremoës, P., Hvitved-Jacobsen, T., Lynggaard-Jensen, A. and Nielsen, B. (1994). Municipal wastewater systems, integrated approach to design, monitoring and control. Wat. Sci. Tech., 29(1), 419-426.

Huisman, L. (2001). Transport and transformation processes in combined sewers. PhD thesis, ETH Zurich, Zurich, Switzerland.

Jeppsson, U., Pons, M.-N., Nopens, I., Alex, J., Copp, J., Gernaey, K.V., Rosen, C., Steyer, J.-P. and Vanrolleghem, P.A. (2007). Benchmark Simulation Model No 2 - General protocol and exploratory case studies. Wat. Sci. Tech., 56(8), 67-78.

Jiang, G., Gutierrez, O., Sharma, K.R. and Yuan, Z. (2010). Effects of nitrite concentration and exposure time on sulfide and methane production in sewer systems. Wat. Res., 44(14), 4241-4251.

Langeveld, J.G., Benedetti, L., de Klein, J.J.M., Nopens, I., Amerlinck, Y, van Nieuwenhuijzen, A., Flameling, T., van Zanten, O. and Weijers, S. (2013). Impact-based integrated real-time control for improvement of the Dommel River water quality. Urb. Wat. J., 10(5), 312-329.

Martin, C. and Vanrolleghem, P.A. (2014). Analysing, completing, and generating influent data for WWTP modelling: A critical review. Env. Mod. Soft., 60, 188-201.

Rauch, W., Bertrand-Krajewski, J.L., Krebs, P., Mark, O., Schilling, W., Schütze, M. and Vanrolleghem, P.A. (2002). Deterministic modelling of integrated urban drainage systems. Wat. Sci. Tech., 45(3), 81-94.

Reichert, P., Borchardt, D., Henze, M., Rauch, W., Shanahan, P., Somlyody, L. and Vanrolleghem, P.A. (2001). River Water Quality Model No.1. IWA Publishing Scientific and Technical Report Series, Technical Report no. 12, London, UK.

Richardson, C.W. (1981). Stochastic simulation of daily precipitation, temperature, and solar radiation. Wat. Resour. Res., 17(1), 182-190.

Rutsch, M., Rieckermann, J. and Krebs, P. (2006). Quantification of sewer leakage: a review. Wat. Sci. Tech., 54(67), 135-144.

Schütze, M., Butler, D. and Beck, M.B. ( 2002). Modelling, Simulation and Control of Urban Wastewater Systems., Springer-Verlag, London, UK.

Snip, L.J.P., Flores-Alsina, X., Plósz, B.G., Jeppsson, U. and Gernaey, K.V. (2014). Modelling the occurrence, transport and fate of pharmaceuticals in wastewater systems. Env. Mod. Soft., 62, 112-127.

Talebizadeh, M., Belia, E. and Vanrolleghem, P.A. (2016). Influent generator for probabilistic modeling of nutrient removal wastewater treatment plants. Env. Mod. Soft., (Accepted). 
Vallet, B. (2011). Modélisation d'un bassin d'orage en vue de l'amélioration de la qualité des rivières par la gestion en temps réel (Modelling a stormwater basin in view of improving river water quality by real-time control). $\mathrm{PhD}$ Thesis, Département de génie civil et de génie des eaux, Université Laval, Québec, QC, Canada.

Vanrolleghem, P., Benedetti, L. and Meirlaen, J. (2005). Modelling and real-time control of the integrated urban wastewater system. Env. Mod. Soft., 20(4), 427-442.

VASYO (2015a).

http://www.vasyd.se/ /media/Documents/Broschyrer/Vatten\%20och\%20avlopp/Avloppsreningsverk\%20och\%20s-kyddsinformation/Sjolunda_wastewater_treatment_plant.ashx (accessed 2015-07-21)

VASYO (2015b).

http://www.vasyd.se/ /media/Documents/Broschyrer/Vatten\%20och\%20avlopp/Avloppsreningsverk\%20och\%20s kyddsinformation/Kallbywastewatertreatmentplant.ashx (accessed 2015-07-21)

Vezzaro, L., Benedetti, L., Gevaert, V., De Keyser, W., Verdonck, F., De Baets, B and Mikkelsen, P.S. (2014). A model library for dynamic transport and fate of micropollutants in integrated urban wastewater and stormwater systems. Env. Mod. Soft., 53, 98-111.

Viessman, W., Lewis, G. and Knapp, J.W. (1989). Introduction to hydrology. Harper \& Row Publishers, New York, NY, USA.

Volcke, E.I.P., van Loosdrecht, M.C.M. and Vanrolleghem, P.A. (2006). Continuity-based model interfacing for plant-wide simulation: A general approach. Wat. Res., 40(15), 2817-2828.

Ward, R.C. and Robinson, M. (2000). Principles of Hydrology. McGraw-Hill Publishing Company, Berkshire, UK.

Weijers, S., Jonge, J., de van Zanten, O., Benedetti, L., Langeveld, J., Menkveld, H. W. and van Nieuwenhuijzen, A. F. (2012). KALLISTO: cost effective and integrated optimization of the urban wastewater system Eindhoven. Wat. Prac. Tech., 7(2). 